\title{
Cascade C-H-Activated Polyannulations toward Ring-Fused Het- eroaromatic Polymers for Intracellular pH Mapping and Cancer Cell Killing
}

\author{
Kang Wang, ${ }^{\dagger,, \#}$ Saisai Yan, ${ }^{\dagger,}, \#$ Ting Han, ${ }^{* \dagger}$ Qian Wu, ${ }^{\dagger,}$ Neng Yan, ${ }^{\|}$Miaomiao Kang, ${ }^{\dagger}$ Jinyin Ge, \\ Dong Wang, , ${ }^{\dagger}$ Ben Zhong Tang ${ }^{*,, \perp}$
}

'Center for AIE Research, Shenzhen Key Laboratory of Polymer Science and Technology, Guangdong Research Center for Interfacial Engineering of Functional Materials, College of Materials Science and Engineering, Shenzhen University, Shenzhen 518060, China

${ }^{\ddagger}$ College of Physics and Optoelectronic Engineering, Shenzhen University, Shenzhen 518060, China

${ }^{\S}$ Department of Chemistry, Hong Kong Branch of Chinese National Engineering Research Center for Tissue Restoration and Reconstruction, The Hong Kong University of Science and Technology, Clear Water Bay, Kowloon, Hong Kong 999077, China

"Environment and State Key Laboratory of Marine Pollution, City University of Hong Kong, Kowloon, Hong Kong 999077, China

${ }^{\perp}$ Shenzhen Institute of Aggregate Science and Technology, School of Science and Engineering, The Chinese University of Hong Kong, Shenzhen, Guangdong 518172, China

KEYWORDS. Heteroaromatic polymers, $C$-H-activated polyannulation, fluorescence sensor, cancer cell killing

\begin{abstract}
The development of straightforward and efficient synthetic methods toward ring-fused heteroaromatic polymers with attractive functionalities has great significance in both chemistry and materials science. Herein, we develop a facile cascade C-Hactivated polyannulation route that can in situ generate multiple ring-fused aza-heteroaromatic polymers from readily available monomers in an atom-economical manner. A series of complex polybenzimidazole derivatives with high absolute molecular weights of up to 24000 are efficiently produced in high yields within 2 hours. Benefiting from their unique imidazole-containing ring-fused structures with multiple aryl pendants, the obtained polymers show excellent thermal and morphological stability, good solution processability, high refractive index, small chromic dispersion, as well as remarkable acid-base-responsive fluorescence. Taking advantage of the ratiometric fluorescence response of the triphenylamine-substituted heteroaromatic polymer to $\mathrm{pH}$ variations, we successfully apply it as a sensitive fluorescence probe for the mapping and quantitative analysis of intracellular $\mathrm{pH}$ changes in live cells. Furthermore, through the simple $\mathrm{N}$-methylation reaction of the ring-fused polybenzimidazoles, diverse azonia-containing polyelectrolytes are readily produced, which can efficiently kill cancer cells via the synergistic effects of dark toxicity and phototoxicity.
\end{abstract}

\section{INTRODUCTION}

Heteroaromatic polymers are an important group of functional functional materials that play an indispensable role in the development of modern society. The presence of plentiful aromatic heterocyclic rings or groups of rings in polymer backbones endow heteroaromatic polymers with unique mechanical properties, outstanding thermal and chemical stability, as well as distinctive electronic and photophysical properties. ${ }^{1}$ Driven by the great demands of the electronic, automobile, manufacturing, and especially aerospace industries in high-temperatureresistant polymers, diverse high-performance heteroaromatic polymers have been developed since the late 1950s. Among various heteroaromatic polymers, polybenzimidazoles (PBIs) with partially or fully aromatic structures have received much attention..$^{2-3}$ In addition to diverse demanding high-temperature applications, the application scope of PBIs has been significantly broadened to organic optoelectronic, electrochemical, and biomedical fields in recent decades. ${ }^{4-6}$ For example, benefitting from the amphoteric nature of benzimidazole groups, functionalized PBIs with $\mathrm{pH}$ responsiveness have been widely explored as ion-sensing units, electrolyte systems, and separators in drug delivery, electrochemical devices, and various gas and liquid separation processes. ${ }^{3,7-8}$ By integrating more (hetero)aromatic rings into the functional imidazole units, the resulting ring-fused PBIs with larger $\pi$-conjugation and distinct electronic structures could show diversified stimuli-responsive capabilities, tunable electrical and photophysical properties, as well as a wide range of interesting biological activities. ${ }^{9-11} \mathrm{Com}-$ pared with the intensive applications of ring-fused heteroaromatic polymers in organic semiconductor materials and electrochemical conversion technologies, their photoluminescence (PL)-related applications have been obviously less explored. Although traditional ring-fused heteroaromatic polymers generally possess good PL properties in the well-dissolved solution states, they often suffer from the issue of poor fluorescence in aggregate states arising from the existence of strong intra-/inter- 
chain $\pi-\pi$ stacking, which greatly hinders their practical applications. ${ }^{12}$ Therefore, it is of great significance to develop and synthesize novel ring-fused PBIs with attractive photophysical properties and explore their potential advanced applications. The most widely adopted method for the synthesis of PBIs is the polycyclocondensations of $o, o^{\prime}$-disubstituted aromatic diamines with aromatic dicarboxylic acids or their derivatives. ${ }^{2-3}$ This polycondensation method is simple but is not conducive to the flexible design and adjustment of heteroaromatic polymer structures. Limited and costly fused (hetero)aromatic substrates, complicated pre-functionalization procedures of aromatic monomers, and elaborate reaction control were often required when this method was applied for the construction of multiple ring- fused PBIs. ${ }^{9}$ The polymer synthesis could be even more challenging when multiple substituents are introduced to decorate the ring-fused heteroaromatic cores. Similar issues also exist with many other commonly used synthetic strategies toward ring-fused heteroaromatic polymers, such as the transitionmetal-catalyzed polycoupling procedures based on Suzuki, Heck, Sonogashira, Stille, or Yamamoto coupling reactions, direct arylation methods, and a series of polycondensation techniques. ${ }^{13-14}$ The synthetic difficulties greatly restrict the accessibility and property investigation of such polymers. It is thus highly desirable to develop facile, straightforward, and efficient polymerization strategies that can in situ generate functional ring-fused aza-heteroaromatic polymers from readily available monomers in a more atom-economical way.

(A) Previous work: cascade oxidative annulation reaction via multiple $\mathrm{C}-\mathrm{H}$ activation
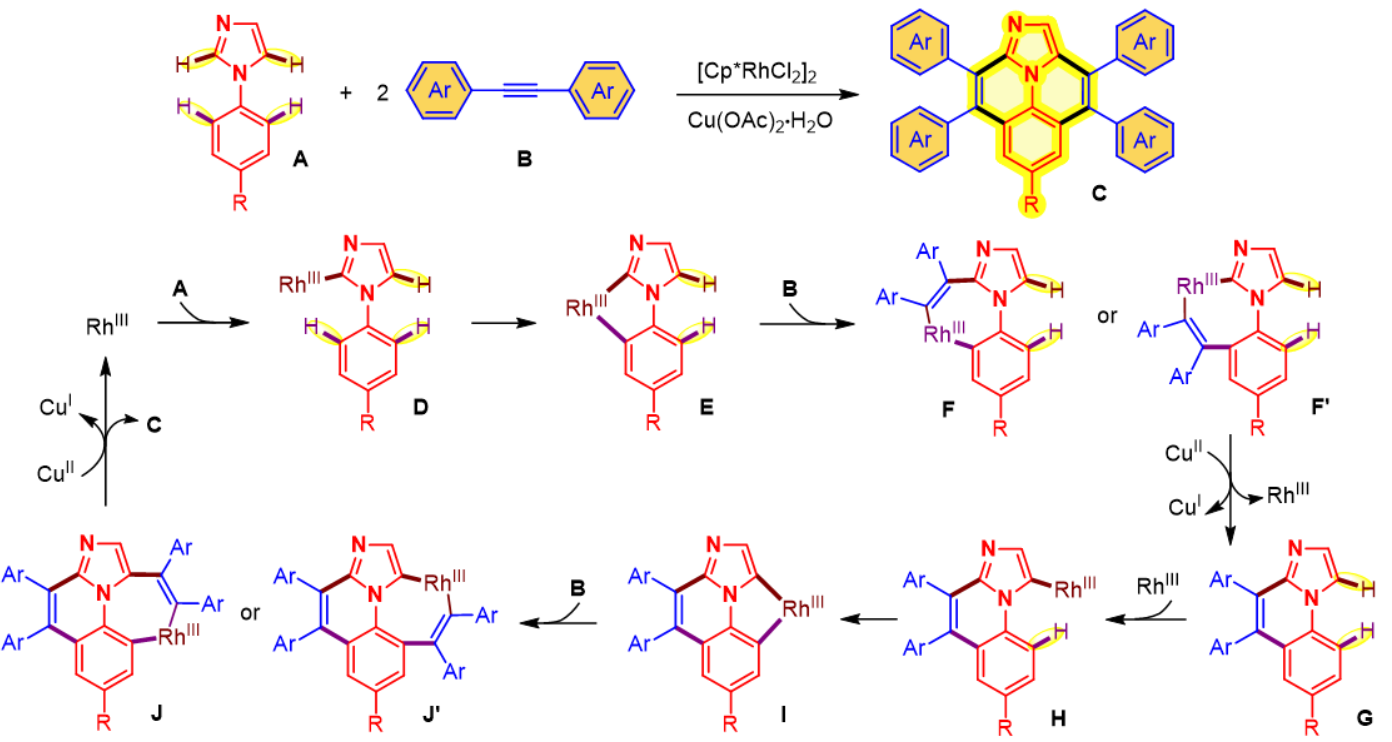

(B) This work: cascade $\mathrm{C}-\mathrm{H}$-activated polyannulation toward ring-fused aza-heteroaromatic polymers

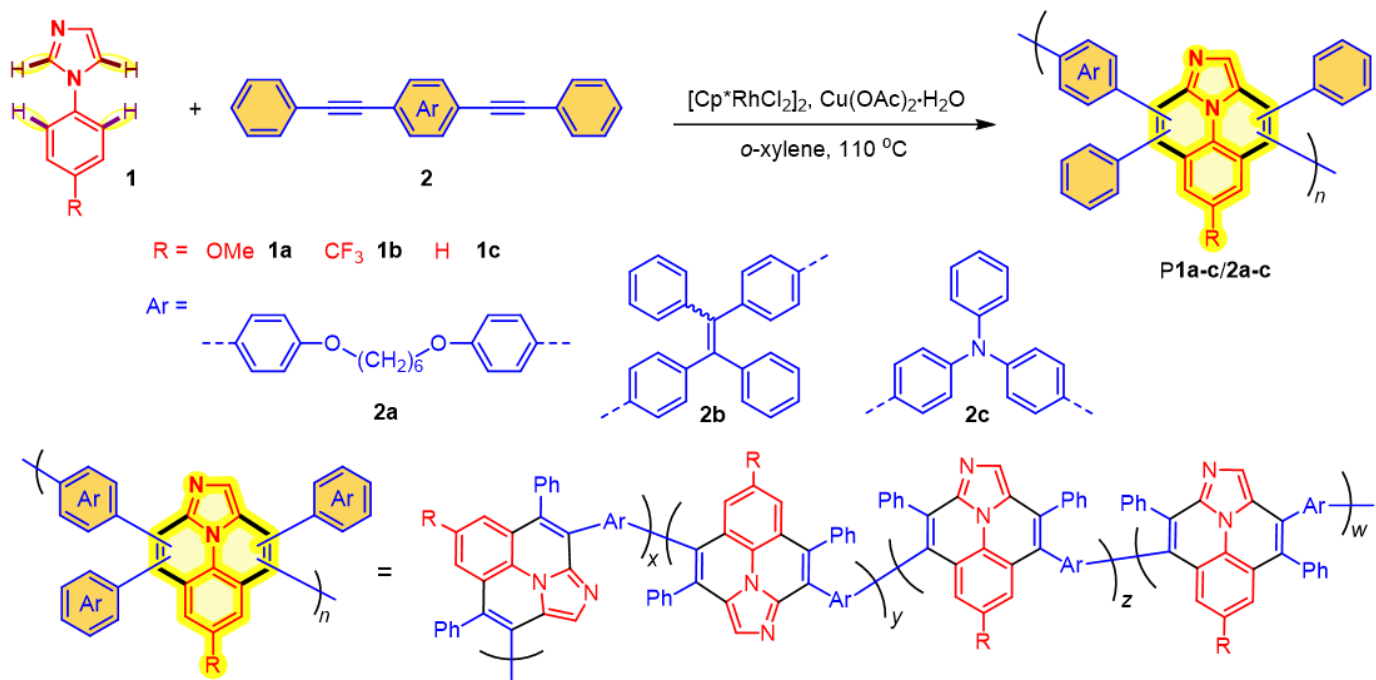

Figure 1. (A) Rhodium(III)-catalyzed cascade oxidative annulation reaction of $N$-aryl-substituted imidazoles with alkynes toward polyheteroaromatic compounds and the corresponding plausible reaction mechanism. ${ }^{26}$ (B) Rhodium(III)-catalyzed cascade C-Hactivated polyannulation reactions of $\mathrm{N}$-aryl-substituted imidazoles and internal diynes for the construction of complex ring-fused aza-heteroaromatic polymers in this work.

Polymerizations are generally developed on the basis of highly efficient small molecular reactions. In organic chemistry, transition metal-catalyzed $\mathrm{C}-\mathrm{H}$ activation reactions have emerged as a powerful tool for the transformation of abundantly existed substrates into a variety of high-value organic compounds. ${ }^{15-16}$ Attracted by the high atom economy, wide substrate scope, high efficiency, and excellent functional group tol- 
erance of $\mathrm{C}-\mathrm{H}$ activation chemistry, polymer chemists have devoted great efforts to applying $\mathrm{C}-\mathrm{H}$ bond activation for the facile synthesis of diverse functional conjugated polymers. ${ }^{17-20} \mathrm{In}$ the past years, several $\mathrm{C}-\mathrm{H}$-activated polyannulations of acetylenic monomers have been developed to construct multifunctional polymers with fused heterocycles. ${ }^{21-25}$ However, most of these polyannulations merely involved one or two $\mathrm{C}-\mathrm{H}$ functionalization sites, consequently leading to the rather limited ring-fused structure diversity in the resulting polymers. Recently, an efficient cascade oxidative annulation reaction of aryl imidazole and alkynes have captured our attention. As depicted in Figure 1A, multiple $\mathrm{C}-\mathrm{H}$ functionalization and annulation processes were involved in this rhodium(III)-catalyzed reaction, and multisubstituted aza-fused polycyclic structures were in situ formed from commercially available and inexpensive reactants. ${ }^{26}$ The introduction of this unique imidazole-containing fused cyclic skeleton into polymer main chains is envisioned to endow the corresponding ring-fused PBIs with a variety of new interesting properties and advanced functionalities. For instance, the presence of multiple aryl substituents around the polycyclic core might distort the rigid polymer structure and effectively isolate the planar units to prevent the occurrence of strong $\pi-\pi$ interactions, thus enabling the polymers to show efficient aggregate-state fluorescence. Besides, the postmodification and acid-base-responsive capabilities of imidazole moieties may allow the polymers to undergo further structure transformations, which not only can effectively enrich the structural diversity of ring-fused aza-heteroaromatic polymers, but also provides possibility for further adjusting their photophysical properties and expanding their application scope

With these concerns in mind, herein we explored the possibility of developing this cascade oxidative annulation reaction into a facile and straightforward polymerization strategy for the in situ generation of multiple ring-fused aza-heteroaromatic polymers. As shown in Figure 1B, the rhodium(III)-catalyzed cascade $\mathrm{C}-\mathrm{H}$-activated polyannulations can efficiently transform the readily available $N$-aryl-substituted imidazoles and internal diynes into a series of ring-fused PBIs with complex structures in an atom-economical manner. Due to their unique imidazole-containing ring-fused structures with multiple aryl pendants, the obtained polymers possess many attractive properties such as good solubility, high thermal and morphological stability, high refractive index and small chromic dispersion, as well as remarkable acid-base-responsive fluorescence in aggregate states. Through the simple $N$-alkylation postmodification, these ring-fused PBIs can be readily converted to diverse azonia-containing polyelectrolytes. Based on the ratiometric fluorescence response of the aza-heteroaromatic polymer to $\mathrm{pH}$ variations and the high reactive oxygen species (ROS) generation efficiency of the cationic polyelectrolyte, their applications in intracellular $\mathrm{pH}$ mapping and photodynamic killing of cancer cells are investigated in this work.

\section{RESULTS AND DISCUSSION Polymerization}

Monomers 1a-1c used in this work were commercially available and used without further purification. Internal diynes $\mathbf{2 a -}$ 2c were facilely synthesized according to the previously reported procedures. ${ }^{27}$ To develop the $\mathrm{C}-\mathrm{H}$-activated cascade polyannulation, the polymerization conditions were first optimized with 1-(4-methoxyphenyl)-1H-imidazole (1a) and internal diyne $\mathbf{2} \mathbf{a}$ as model monomers. In the first attempt, the polymerization of $\mathbf{1 a}(0.2 \mathrm{M})$ and $2 \mathbf{a}(0.2 \mathrm{M})$ was carried out in toluene under $\mathrm{N}_{2}$ at $110{ }^{\circ} \mathrm{C}$ in the presence of $\left[\mathrm{Cp} * \mathrm{RhCl}_{2}\right]_{2}(10 \mathrm{~mol} \%)$ and $\mathrm{Cu}(\mathrm{OAc})_{2} \cdot \mathrm{H}_{2} \mathrm{O}$ (8 equiv.).However, insoluble products were formed in the reaction mixture after reacting for $24 \mathrm{~h}$. The reaction time was then gradually shortened. After polymerizing for 2 hours, soluble P1a/2a with a number-average molecular weight $\left(M_{\mathrm{n}}\right)$ of 8300 and weight-average molecular weight $\left(M_{\mathrm{w}}\right)$ of 14700 was obtained in a moderate yield of $56.7 \%$ (Table S1). To obtain polymers with higher molecular weights in better yields, the effect of catalyst loading was then investigated. When the amount of $\left[\mathrm{Cp}^{*} \mathrm{RhCl}_{2}\right]_{2}$ was increased from $10 \mathrm{~mol} \%$ to $40 \mathrm{~mol} \%, \mathrm{P} 1 \mathrm{a} / \mathbf{2 a}$ with a higher $M_{\mathrm{n}}(11100)$ and a lower polydispersity $(\fallingdotseq=1.3)$ was afforded in a high yield of $99.2 \%$ (Table S2). Decreasing the amount of $\left[\mathrm{Cp}^{*} \mathrm{RhCl}_{2}\right]_{2}$ resulted in a decrease in either molecular weights or reaction yields (Table S2). We next examined the solvent effect with the optimized catalyst loading at 2 hours. The results in Table S3 suggested that the polymerization of $\mathbf{1 a}$ and $\mathbf{2 a}$ proceeded efficiently in toluene, $o$-dichlorobenzene, and $o$-xylene. Considering the relatively higher $M_{\mathrm{n}}$ of the polymeric product, $o$-xylene was selected as the optimal solvent among the tested conditions for this polymerization. The effects of catalyst amount and monomer ratio on the polymerization were also studied. As summarized in Table S4 and Table S5, decreasing the amount of $\mathrm{Cu}(\mathrm{OAc})_{2} \cdot \mathrm{H}_{2} \mathrm{O}$ led to a simultaneous decrease in $M_{\mathrm{n}}$ and $M_{\mathrm{w}}$, and the polymerization using the theoretical monomer feeding ratio of 1:1 displayed the best reactivity. The presence of an excess amount of 1a had little effect on reaction yield but reduced the molecular weights of polymers, while the excessive use of 2a obviously decreased the polymerization efficiency.

In order to test the application scope of the polymerization and meanwhile enrich the polymer functionalities, we next conducted the polymerizations of different phenylimidazoles and internal diynes under the optimized reaction conditions. Various internal diynes, including $\mathbf{2 a}$ with flexible alkyl chain and $\mathbf{2 b - c}$ with rigid conjugated spacers of tetraphenylethene (TPE) or triphenylamine (TPA) luminophore, were applied to the polymerizations with 1a. A series of fused aza-heterocyclic polymers were obtained in high yields (Table 1, entries 1-3). The best polymerization results of $\mathbf{1 a} / \mathbf{2} \mathbf{a}$ among the combination of $\mathbf{1 a} / \mathbf{2 a}-\mathbf{c}$ is probably due to the better solubility of $\mathrm{P} \mathbf{1 a} / \mathbf{2 a}$ in $o$ xylene than the other two polymers, which promotes the smooth progress of this polymerization. The effect of different phenylimidazoles on the polymerization was also explored. When the OMe-substituted phenylimidazole (1a) was replaced with the $\mathrm{CF}_{3}$-substituted phenylimidazole (1b) to polymerize with $\mathbf{2 a - c , ~ P 1 b / 2 a - c ~ w i t h ~ h i g h e r ~ m o l e c u l a r ~ w e i g h t s ~ t h a n ~ t h o s e ~ o f ~}$ P1a/2a-c were formed in good yields. The polymerization of 1phenylimidazole (1c) with $\mathbf{2 a}$ can also afford polymeric product in a high yield. These results indicated that we successfully developed a direct and efficient polymerization tool for the in-situ construction of diverse ring-fused aza-heteroaromatic polymers. 
Table 1. Polymerization results of different monomers ${ }^{a}$

\begin{tabular}{cccccc}
\hline entry & polymer & yield $(\%)$ & $M_{\mathrm{n}}{ }^{b}(\mathrm{MALLS})^{c}$ & $M_{\mathrm{w}}{ }^{b}(\mathrm{MALLS})^{c}$ & $\Xi^{b}(\mathrm{MALLS})^{c}$ \\
\hline 1 & $\mathrm{P} \mathbf{1 a} / \mathbf{2 a}$ & 99.6 & $12300(8300)$ & $14700(14500)$ & $1.2(1.7)$ \\
2 & $\mathrm{P} \mathbf{1 a} / \mathbf{2 b}$ & 96.0 & $8100(5000)$ & $10300(9900)$ & $1.2(1.2)$ \\
3 & $\mathrm{P} \mathbf{a} / \mathbf{2 c}$ & 86.7 & $8400(6100)$ & $30900(24000)$ & $1.2(1.6)$ \\
4 & $\mathrm{P} \mathbf{1 b} / \mathbf{2 a}$ & 82.0 & $25200(12800)$ & $23000(15100)$ & $1.2(1.9)$ \\
5 & $\mathrm{P} \mathbf{b} / \mathbf{2 b}$ & 87.6 & $19900(10300)$ & $21200(17700)$ & $1.2(1.5)$ \\
6 & $\mathrm{P} \mathbf{1 b} / \mathbf{2 c}$ & 89.0 & $17700(12000)$ & $16200(13200)$ & $1.2(1.5)$ \\
7 & $\mathrm{P} \mathbf{c} / \mathbf{2 a}$ & 92.1 & $11900(8900)$ & $1.4(1.5)$ \\
\hline
\end{tabular}

${ }^{a}$ Carried out at $110{ }^{\circ} \mathrm{C}$ in $o$-xylene under $\mathrm{N}_{2}$ for 2 hours. $[\mathbf{1}]=[\mathbf{2}]=0.2 \mathrm{M},\left[\mathrm{Cp}^{*} \mathrm{RhCl}_{2}\right]_{2}=40 \mathrm{~mol} \%, \mathrm{Cu}(\mathrm{OAc})_{2} \cdot \mathrm{H}_{2} \mathrm{O}=8$ equiv. ${ }^{b} \mathrm{Determined}$ by GPC in DMF on the basis of a linear polystyrene calibration. $Đ=$ polydispersity $=M_{\mathrm{w}} / M_{\mathrm{n}}{ }^{c}$ Absolute molecular weights determined by GPC with a MALLS detector in DMF.

\section{Structure Characterization}

To assist the structural characterization of the obtained polymers, model compound $\mathbf{3}$ was prepared by the reaction of $\mathbf{1 a}$ and diphenylacetylene under conditions similar to those for polymerizations (Scheme S1). The structure of $\mathbf{3}$ was confirmed by high-resolution mass spectrometry (HRMS, Figure S1), IR (Figure S2), and NMR analysis (Figure 2). Single crystals of 3 were obtained from slow evaporation of its dichloromethane/hexane mixture, whose structure was confirmed by Xray diffraction analysis. All polymers and their corresponding monomers were fully characterized by IR and NMR spectroscopies (see Supplementary Methods for details, Figures S3-S9). Taking P1a/2a as a representative example for structural analysis, the characteristic absorption peak of the $\mathrm{C} \equiv \mathrm{C}$ group of $\mathbf{2 a}$ disappeared in the IR spectra of $\mathbf{3}$ and P1a/2a (Figure S2), indicating the consumption of $\mathrm{C} \equiv \mathrm{C}$ group by the model reaction and the polymerization. Regarding the ${ }^{1} \mathrm{H}$ NMR results (Figure $2 \mathrm{~A}$ D), the resonance peaks at $\delta 7.02,7.28$, and $7.17 \mathrm{ppm}$ can be assigned to the activated $\mathrm{C}-\mathrm{H}$ protons at position "a", "b", and

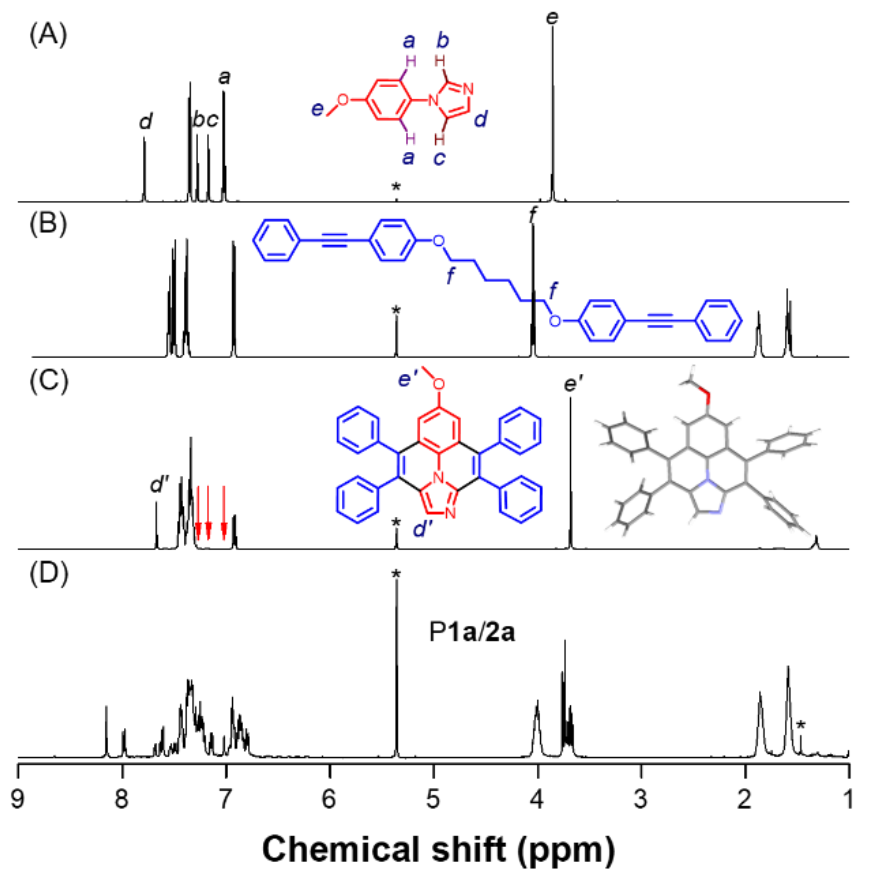

"c", respectively, in 1a. These peaks were not observed in the ${ }^{1} \mathrm{H}$ NMR spectra of 3. Meanwhile, the signals related to proton "c" at $\delta 7.79$ and "e" at $\delta 3.86$ in 1a slightly shifted after reaction. These results indicated the occurrence of the model reaction and the polymerization. The ${ }^{13} \mathrm{C}$ NMR results shown in Figure $2 \mathrm{E}$ $\mathrm{H}$ further verified the polymer structure. The resonance peaks of the acetylene carbon atoms (position "i" and "j") of $\mathbf{2 a}$ were hardly detected in the ${ }^{13} \mathrm{C}$ NMR spectrum of P1a/2a. Instead, many new peaks related to the aromatic carbon atoms were observed in the polymer structure, indicating the formation of new cyclized units. Similar features were also observed in the characterization results of the other polymers (Figures S3-S9). The IR and NMR spectra of the polymers largely resembled those of the model compound 3 . The comparison between the NMR spectra of $\mathbf{3}$ and polymers suggested that there are different regio-isomeric units in polymer backbones. All these characterization results confirmed the successful synthesis of the targeted polymer structures as shown in Figure 1B.

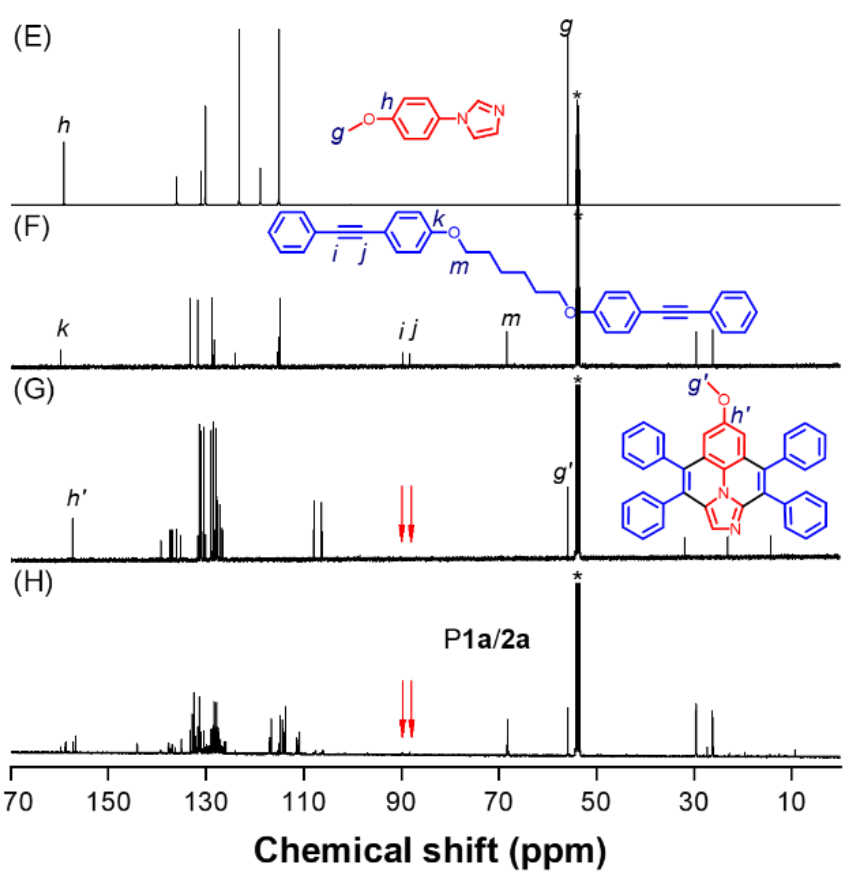

Figure 2. (A-D) ${ }^{1} \mathrm{H}$ NMR spectra of (A) 1a, (B) 2a, (C) model compound 3, and (D) P1a/2a in $\mathrm{CD}_{2} \mathrm{Cl}_{2}$. Inset in (C): single crystal structure of model compound 3 (CCDC number 2116306). (E-H) ${ }^{13} \mathrm{C}$ NMR spectra of (E) 1a, $(\mathrm{F}) \mathbf{2 a},(\mathrm{G})$ model compound 3, and $(\mathrm{H}) \mathrm{P} \mathbf{1 a} / \mathbf{2 a}$ in $\mathrm{CD}_{2} \mathrm{Cl}_{2}$. The solvent peaks are marked with asterisks. 


\section{Thermal Properties and Light Refraction}

Polymers with high thermal decomposition temperature $\left(T_{\mathrm{d}}\right)$ and high char yield are desirable materials for high-temperature applications. ${ }^{28-30}$ The thermogravimetric analysis (TGA) results of P1a-c/2a-c suggested that all these polymers possess excellent thermal stability due to their rigid ring-fused heteroaromatic structures. As shown in Figure $3 \mathrm{~A}$, the $T_{\mathrm{d}}$ values of P1ac/2a-c at $5 \%$ weight loss can reach up to $522^{\circ} \mathrm{C}$, which are much better than most of commercial pure polymeric materials. Noteworthy, the TPE-containing polymers (P1a-b/2b) and the TPAcontaining polymers $(\mathrm{P} \mathbf{1} \mathbf{a}-\mathbf{b} / \mathbf{2 c})$ retain more than $70 \%$ of their weights at a high temperature of up to $800{ }^{\circ} \mathrm{C}$ as a result of their conjugated structures. Moreover, the differential scanning calorimetry (DSC) analysis shown in Figure 3B demonstrated the high morphological stability of the polymers with high glass transition temperatures $\left(T_{\mathrm{g}}\right)$ of up to $315^{\circ} \mathrm{C}$. The high $T_{\mathrm{d}}$ and char yields as well as excellent morphological stability of these polymers make them potentially suitable for various demanding high-temperature or flame-retardant applications in aerospace industry and other fields.
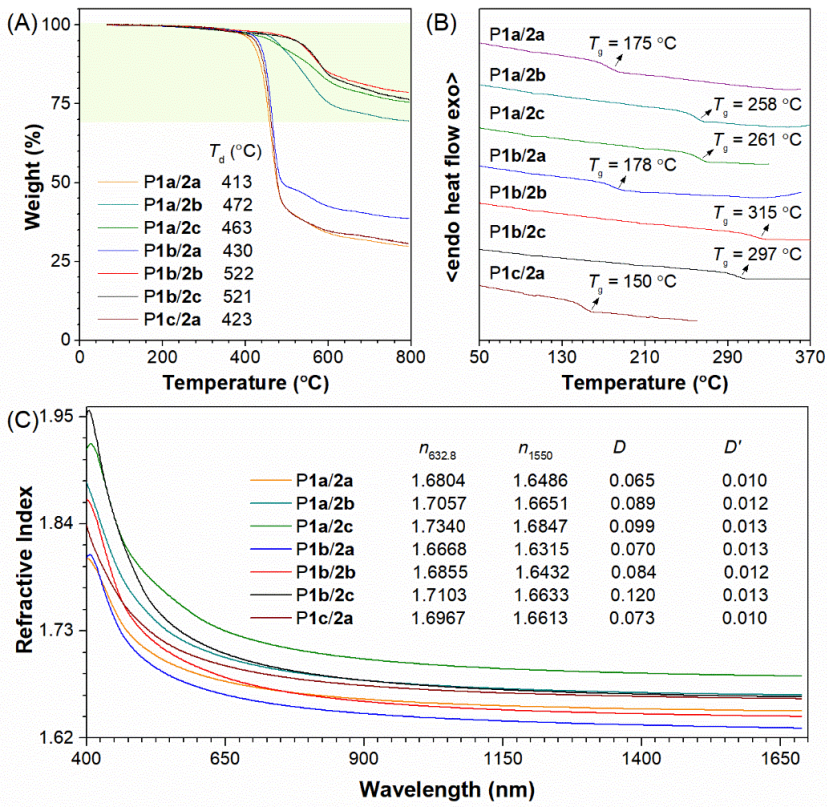

Figure 3. (A) TGA thermograms of $\mathrm{P} \mathbf{1} / \mathbf{2}$ collected under nitrogen at a heating rate of $10{ }^{\circ} \mathrm{C} / \mathrm{min}$. (B) DSC curves of $\mathrm{P} \mathbf{1} / \mathbf{2}$ recorded under nitrogen during the second heating scan at a heating rate of $10{ }^{\circ} \mathrm{C} / \mathrm{min} . T_{\mathrm{d}}=$ decomposition temperature at $5 \%$ weight loss; $T_{\mathrm{g}}$ $=$ glass transition temperature (C) Wavelength dependence of refractive indices of P1/2 thin films. Abbreviation: $n=$ refractive index; $D=$ chromatic dispersion in the visible region $=\left(n_{\mathrm{F}}-n_{\mathrm{C}}\right) /\left(n_{\mathrm{D}}\right.$ -1 ), where $n_{\mathrm{D}}, n_{\mathrm{F}}$, and $n_{\mathrm{C}}$ are the $n$ values at wavelengths of Fraunhofer D, F, and C spectral lines of 589.2, 486.1, and $656.3 \mathrm{~nm}$, respectively; $D^{\prime}=$ chromatic dispersion in the IR region $=\left(n_{1064}-\right.$ $\left.n_{1550}\right) /\left(n_{1319}-1\right)$, where $n_{1064}, n_{1319}$, and $n_{1550}$ are the $n$ values at 1064,1319 , and $1550 \mathrm{~nm}$, respectively.

Heteroaromatic polymers often suffer from a difficult balance between their thermal stability and processability. However, all of the highly thermal stable polymers obtained in this work possess excellent solubility in common organic solvents, such as tetrahydrofuran (THF), dichloromethane, chloroform, $\mathrm{N}, \mathrm{N}$-dimethylformamide (DMF), 1,2-dichloroethane (DCE), etc. Uniform thin films can be readily fabricated by spin-coating the DCE solutions of the polymers on silicon wafers. Considering the good film-forming ability and the potential contribution of the ring-fused heteroaromatic rings on refractive index, ${ }^{31}$ we then investigated the light refraction properties of these polymers. The results demonstrate that all polymers have high refractive index $(n)$ values of 1.9565-1.6301 in a wide wavelength region of 400-1700 $\mathrm{nm}$ (Figure 3C). Their $n$ values at $632.8 \mathrm{~nm}\left(n_{632.8}\right)$ are in the range of $1.6668-1.7340$, which are much higher than those of the commercially important optical plastics $(n=\sim 1.50-1.60){ }^{32}$ The $D$ and $D$ ' values of these polymers are calculated to be in the range of $0.065-0.120$ and $0.010-0.013$, respectively, indicating their small dispersions in both the visible region and the IR region. The excellent thermal properties, good solution processability, high refractive index, as well as low chromatic aberration of these ring-fused heteroaromatic polymers enable them to find promising applications in advanced optoelectronic devices such as heat-resistant optical coatings. ${ }^{33}$

\section{Postmodification and Photophysical Properties}

Postmodification is a simple and effective way to produce polymers with complicated structures. Taking advantage of the imidazole structure, we tried to post-modify the obtained polymers with iodomethane $\left(\mathrm{CH}_{3} \mathrm{I}\right)$ to afford the structurally diverse polyelectrolytes. To test the reactivity of the benzo[ $i j]$ imidazo[2,1,5-de]quinolizine scaffold, model compound $\mathbf{3}$ was first used to react with $\mathrm{CH}_{3} \mathrm{I}$ (Figure $4 \mathrm{~A}$ ). The results showed that compound $\mathbf{3}$ was methylated within short time to generate a charged fused heterocyclic compound (3-I) in a nearly quantitative yield. The structure of 3-I was confirmed by HRMS (Figure S10) and NMR analysis (Figure S11). Encouraged by the high efficiency of the methylation reaction, we then explored the post-modification capabilities of the polymers (P1a-b/2a-c) under similar conditions (Figure 4B). The structural characterization results (Figure S12-S15) suggested that these fused azaheterocyclic polymers can be converted into a series of azoniacontaining polyelectrolytes $(\mathrm{P} \mathbf{1} \mathbf{a}-\mathbf{b} / \mathbf{2 a}-\mathbf{c}-\mathbf{I})$ through the facile postmodification reaction. This feature not only enriches the diversity of polymer structures, but also provides possibility for further expanding the function of ring-fused heteroaromatic polymers.

Organic luminescent materials with efficient fluorescence in aggregate states are in great demand due to their significance in diverse practical applications. ${ }^{34-35} \mathrm{We}$ next investigated the photophysical properties of the model compounds and polymers with multisubstituted fused heterocycles. As shown in Figure S16, the onset absorption wavelength $\left(\lambda_{\text {onset }}\right)$ of model compound 3 and P1a-c/2a-c were in the range of $445-468 \mathrm{~nm}$. After the methylation reaction, the obtained model compound 3-I and P1a-b/2a-c-I exhibited $\lambda_{\text {onset }}$ in the range of $428-476 \mathrm{~nm}$. The PL property of model compound $\mathbf{3}$ in THF/water mixtures with different water fractions $\left(f_{\mathrm{w}}\right)$ was shown in Figure $4 \mathrm{C}$. The solution state of $\mathbf{3}$ and its aggregate states at different $f_{\mathrm{w}}$ exhibited comparable emission intensity. Similar tendency was also observed in the PL spectra of the cationic compound 3-I (Figure 4D). The dual-state intense emission of $\mathbf{3}$ and $\mathbf{3}$-I validated our expectation. The large rigid and conjugated polycyclic core resulted in their efficient fluorescence in dilute solutions, while the presence of multiple aromatic substituents weakened the $\pi$ $\pi$ stacking, thus making them possible to maintain the good PL properties in aggregate states. The luminescence properties of the polymers (P1a-b/2a-c and P1a-b/2a-c-I) in different states were also characterized. As depicted in Figure 4E-H, all these polymers exhibited good emission intensity in both solution and aggregate states. Interestingly, the emission color of the meth- 
ylated products of model compound $\mathbf{3}$ and P1a/2a showed a remarkable blue shift from green to blue no matter in solution or in aggregates (Figure 4C-E). In contrast, there was little change in fluorescence color for the solution and aggregates of the TPE-containing polymers $(\mathrm{P} \mathbf{1} \mathbf{a} / \mathbf{2 b})$ before and after methylation (Figure 4F), while an obvious red shift occurred for the fluorescence of TPA-containing polymers (P1a/2c and P1b/2c) after methylation (Figure $4 \mathrm{G}$ and $4 \mathrm{H}$ ). As shown in Figure $4 \mathrm{G}$, compared with P1a/2c, the fluorescence color of P1a/2c-I obviously shifted from green with a maximum emission wavelength $\left(\lambda_{\mathrm{em}}\right)$ at $510 \mathrm{~nm}$ to orange red $\left(\lambda_{\mathrm{em}}=636 \mathrm{~nm}\right)$ in both solution and aggregates. These results indicated that the PL properties of the fused aza-heterocyclic polymers can be readily tuned through the postmodification reaction.
(A)

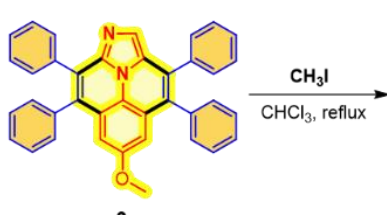

3

(C)

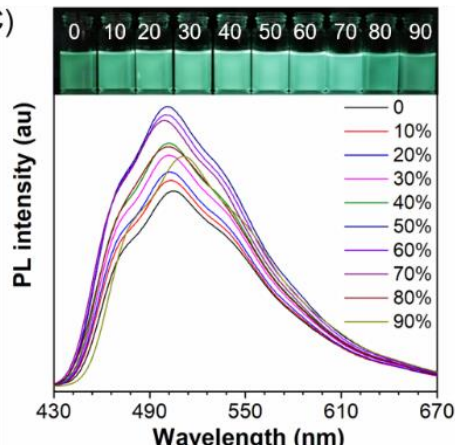

(F)

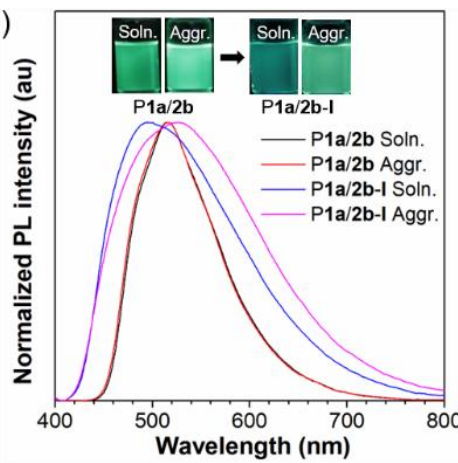

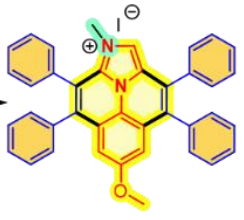

3-I
(B)

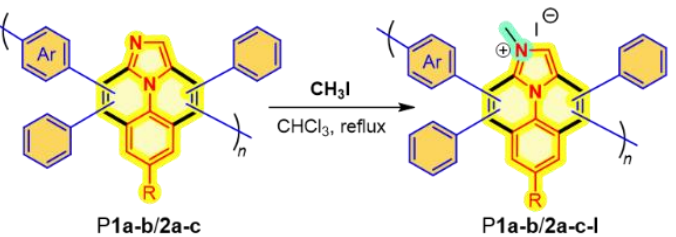

(D)

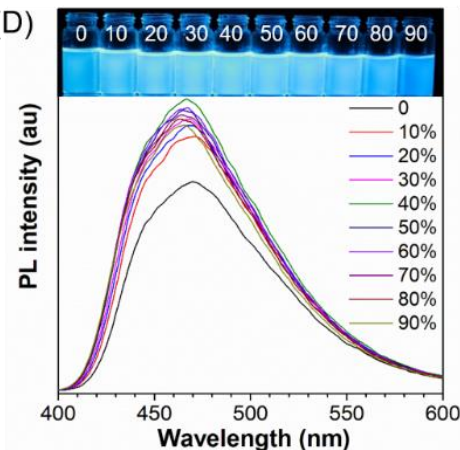

(E)

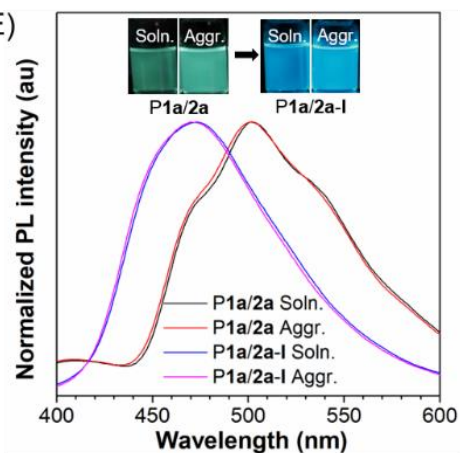

(G)

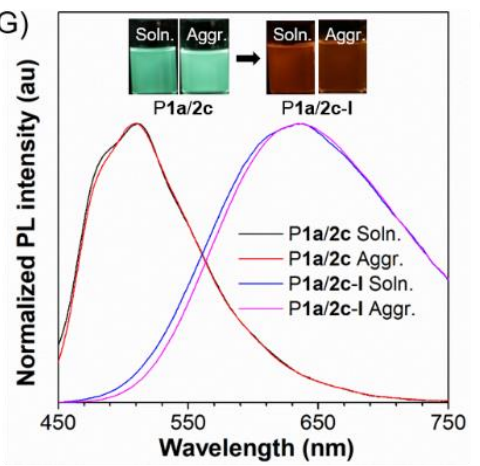

(H)

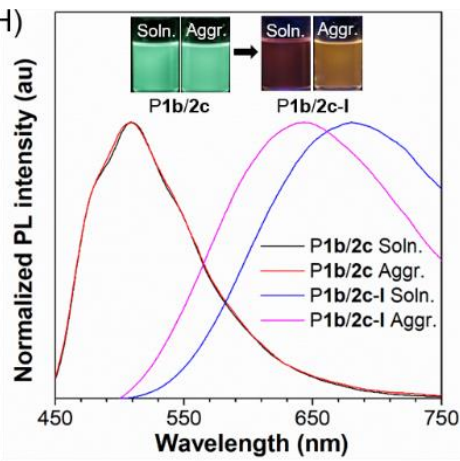

Figure 4. (A) Methylation reaction of model compound 3. (B) Postmodification of polymers P1a-b/2a-c by $\mathrm{CH}_{3} \mathrm{I}$ to afford azonia-containing fused cyclic polyelectrolytes. (C) Photoluminescence (PL) spectra of model compound 3 in THF and THF/water mixtures with different water fractions $\left(f_{\mathrm{w}}\right)$. Inset: the associated fluorescent photographs. (D) PL spectra of the methylated model compound (3-I) in DMSO and $\mathrm{DMSO} /$ water mixtures with different $f_{\mathrm{w}}$. Inset: the associated fluorescent photographs. $(\mathrm{E}-\mathrm{H})$ The normalized PL spectra and the associated fluorescent photographs of the solution (soln.) and aggregates (aggr.) of (E) P1a/2a and P1a/2a-I, (F) P1a/2b and P1a/2b-I, (G) P1a/2c and $\mathrm{P} 1 \mathbf{a} / \mathbf{2 c}-\mathbf{I}$, and $(\mathrm{H}) \mathrm{P} \mathbf{1 b} / \mathbf{2 c}$ and P1b/2c-I. All fluorescent photographs were taken under $365 \mathrm{~nm} \mathrm{UV}$ irradiation. Solution concentration: 10 $\mu \mathrm{M}$; excitation wavelength: $340 \mathrm{~nm}$.

\section{Acid-Base-Responsive Fluorescence}

Inspired by the abovementioned results, we then investigated the potential protonation-induced photophysical changes of these imidazole-containing polymers. As shown in Figure S17S18 and Figure 5, the aggregates of compound $\mathbf{3}$ and P1a-b/2bc showed similar fluorescence change in terms of the emission color after being acidified compared to the methylation treatment. For example, the fluorescence of model compound $\mathbf{3}$ and P1a/2a obviously changed from green $\left(\lambda_{\mathrm{em}}=\sim 500 \mathrm{~nm}\right)$ to blue $\left(\lambda_{\mathrm{em}}=\sim 470 \mathrm{~nm}\right)$ upon adding trifluoroacetic acid (TFA) into their aggregates in aqueous solutions (Figure 5A and Figure S18A). On the other hand, after being protonated by TFA, the $\lambda_{\text {em }}$ of P1a/2c aggregates remarkably red-shifted from 510 to $616 \mathrm{~nm}$ accompanied with a significant decrease in PL intensity (Figure 5B). The variation tendency in absorption wavelength after protonation was consistent with that of fluorescence. After adding $\mathrm{NaOH}$ solution into the acidified mixture, both the PL and the absorption spectra could well restore to the original state possibly due to the deprotonation process. Among the tested polymers, P1a/2c showed the most obvious fluorescence change in response to acid and base. We thus chose $\mathrm{P} \mathbf{1 a} / \mathbf{2 c}$ as a potential fluorescence sensor to carry out in-depth exploration of its acid-base responsive behavior. The reversibility and reliability of this sensing system was examined by alternatively adding TFA and $\mathrm{NaOH}$ solution. As depicted in Figure 5B and $5 \mathrm{C}$, the bright green fluorescence and weak orange fluorescence states of $\mathbf{P} \mathbf{1 a} / \mathbf{2 c}$ could interconvert for at least seven consecutive cycles with negligible fatigue, demonstrating its excellent reversibility and repeatability.

To reveal the mechanism of the acid-base-responsive fluorescence, the ${ }^{1} \mathrm{H}$ NMR spectra of $\mathbf{3}$ and $\mathrm{P} \mathbf{1} \mathbf{a} / \mathbf{2 c}$ after adding TFA 
and the subsequent addition of $\mathrm{NaOH}$ were monitored. As shown in Figure S19, after acidification with TFA, the characteristic peaks of 3 at $\delta 7.56,6.73$ and 6.70 shifted to the lower field at $\delta 8.03,6.91$ and 6.90, respectively. The subsequent addition of $\mathrm{NaOH}$ led to the complete restore of the resonance peaks to their original positions. Similar phenomena were also observed in the ${ }^{1} \mathrm{H}$ NMR spectra of P1a/2c (Figure S20). These results indicated that the protonation and deprotonation process indeed occurred on these imidazole-containing structures (Figure S21). The excellent reversibility in basic conditions demonstrated that these processes were nondestructive to molecular structures. Furthermore, the influence of the protonated structures on the PL properties of polymers was investigated by the time-dependent density functional theory (TD-DFT) calculations via Gaussian 09. Due to the complexity of polymers, the repeating unit structures $(\mathbf{3}, \mathbf{3}-\mathbf{H}, \mathbf{M 1 a} / \mathbf{2 c}$, and $\mathrm{M} \mathbf{1 a} / \mathbf{2 c}-\mathbf{H})$ were chosen to simulate the structures of $\mathrm{P} \mathbf{1} \mathbf{a} / \mathbf{2 a}$ and $\mathrm{P} \mathbf{1} \mathbf{a} / \mathbf{2 c}$ before and after protonation, respectively, for the calculations (Figure S22). Natural transition orbitals (NTOs) of these structures were calculated for the excited state analysis and their emission wavelengths were also estimated at the B3LYP/6-31G (d, p) level. As shown in Figure 5D and 5E, the variation trend in the calculated emission wavelength $\left(\lambda_{\text {cal. }}\right)$ was consistent with the experimental results. The separation difference between the hole NTOs and the electron NTOs of $\mathbf{3 - H}$ was a little smaller than that of model compound $\mathbf{3}$, whereas the electron cloud separation degree of M1a/2c-H was much more obvious than that of M1a/2c. The hole NTOs of M1a/2c-H mainly localized on the TPA moiety (strong electron donor) while the electron NTOs mainly distributed on the protonated fused heterocyclic core (strong electron acceptor). Therefore, the different fluorescence response of the polymers to protonation could be explained by their different electronic structures. The structure with stronger donor-acceptor (D-A) effect such as P1a/2c was more conducive to changing its electron cloud distribution after protonation, thus showing significantly red-shifted fluorescence in acidic conditions.

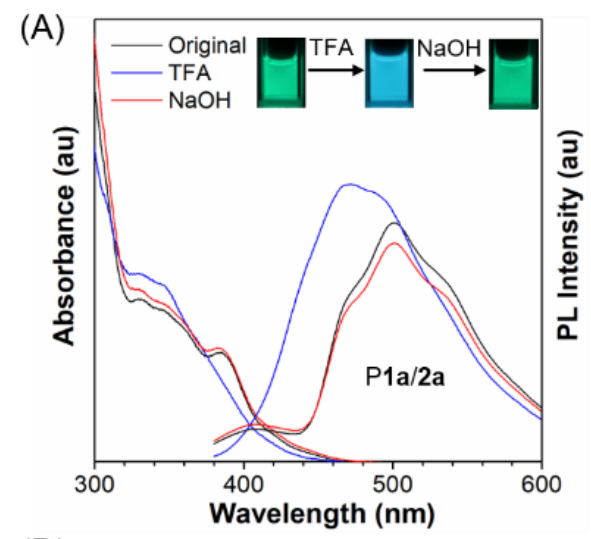

(D)
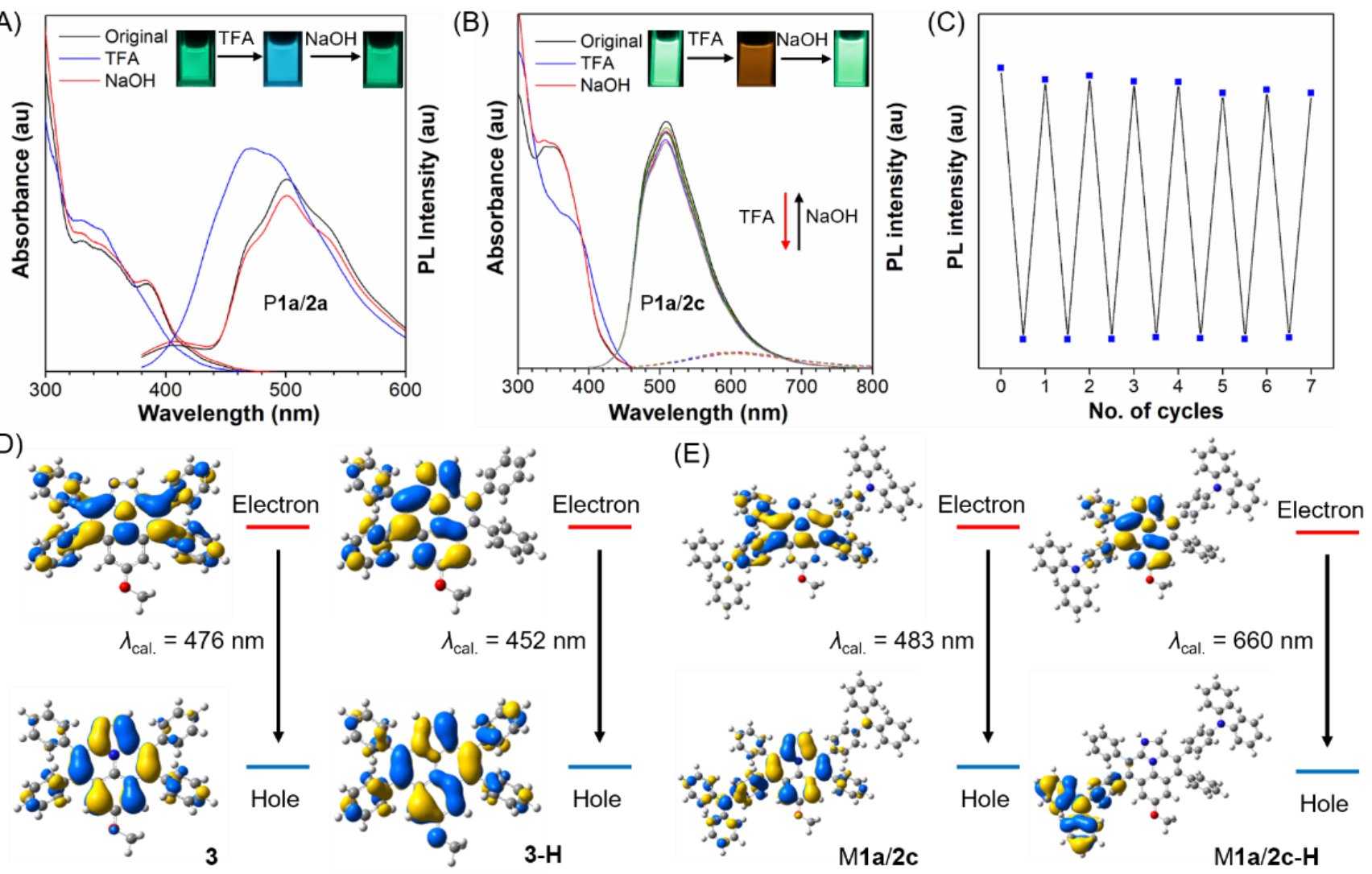

Figure 5. (A and B) Absorption and photoluminescence (PL) spectra of the aggregates of (A) P1a/2a and (B) P1a/2c in aqueous solutions before and after the sequential addition of trifluoroacetic acid (TFA) and NaOH. Inset: fluorescent photographs taken under $365 \mathrm{~nm}$ UV irradiation. Excitation wavelength: $340 \mathrm{~nm}$. (C) Reversible switching of the fluorescence of P1a/2c between bright green and weak orange states by repeatedly adding TFA and $\mathrm{NaOH}$ solution. (D and E) The molecular orbital amplitude plots of electron and hole energy levels of (D) $\mathbf{3}$ and 3-H and (E) M1a/2c and M1a/2c-H in the excited state $\left(\mathrm{S}_{1}\right)$ and their simulated emission wavelengths calculated using the (TD) B3LYP/6-31G (d, p) method.

\section{Ratiometric Fluorescence Sensing of Intracellular pH}

The remarkably redshifted and weakened fluorescence of $\mathrm{P} 1 \mathrm{a} / \mathbf{2 c}$ in response to acidic conditions suggested that it may serve as a promising ratiometric $\mathrm{pH}$ sensor. We thus measured the $\mathrm{pH}$-dependent emission spectra of $\mathrm{P} \mathbf{1 a} / \mathbf{2} \mathbf{c}$ in buffer solutions with $\mathrm{pH}$ ranging from 7.83 to 1.06. As shown in Figure 6A, with the gradual decrease in $\mathrm{pH}$, the emission intensity of $\mathbf{P} \mathbf{1 a} / \mathbf{2 c}$ at $510 \mathrm{~nm}$ steadily decreased while that at $616 \mathrm{~nm}$ increased. Meanwhile, an obvious change in the fluorescence color of
$\mathrm{P} 1 \mathrm{a} / 2 \mathrm{c}$ was observed from bright green to dark yellow and then to orange-red as the $\mathrm{pH}$ varied from 7.02 to 1.44 (inset in Figure $6 \mathrm{~B})$. The change in the emission intensity ratio $\left(I_{510 \mathrm{~nm}} / I_{616 \mathrm{~nm}}\right)$ of $\mathrm{P} 1 \mathrm{a} / 2 \mathrm{c}$ was analyzed as a function of $\mathrm{pH}$ value. Figure $6 \mathrm{~B}$ shows the sigmoidal fitting curve of $I_{510 \mathrm{~nm}} / I_{616 \mathrm{~nm}}$ versus $\mathrm{pH}$, which indicated that this ratiometric $\mathrm{pH}$ sensor is highly sensitive in a wide $\mathrm{pH}$ range of 2.0-6.0. Intracellular $\mathrm{pH}$ plays a vital role in many cellular events, such as cell proliferation and apoptosis, endocytosis, protein degradation, enzyme activity, and calcium regulation. ${ }^{36-38}$ Important subcellular organelles such as 
mitochondria, lysosomes and Golgi possess different $\mathrm{pH}$ distribution and distinct physiological functions. For example, along the endocytic pathways in a typical mammalian cell, the $\mathrm{pH}$ in mitochondria, cytosol and the nucleus is over 7.0, whereas the $\mathrm{pH}$ in acidic organelles such as endosomes and lysosomes varies from 6.5 to $4.5 .{ }^{39-40}$ Many common diseases are related to the abnormal values of $\mathrm{pH}$ in acidic organelles. Hence, the development of efficient platforms for the sensing of intracellular $\mathrm{pH}$ changes is of great significance and may assist the better understanding of diverse cellular behaviors. ${ }^{41-42}$ Considering the ratiometric fluorescence response of $\mathrm{P} \mathbf{1 a} / \mathbf{2 c}$ to $\mathrm{pH}$ change, we then tried the possibility of applying $\mathrm{P} \mathbf{1} \mathbf{a} / \mathbf{2} \mathbf{c}$ for the sensing and quantitative determination of intracellular $\mathrm{pH}$ values.

To facilitate the intracellular $\mathrm{pH}$ sensing, $\mathrm{P} 1 \mathrm{a} / \mathbf{2 c}$ nanoparticles (NPs) with effective diameters of $67 \mathrm{~nm}$ were prepared (Figure S23). The cell staining capability of P1a/2c NPs was first examined using a confocal laser scanning microscope (CLSM). As shown in Figure S24, bright fluorescence was observed in the cytoplasm of $4 \mathrm{~T} 1$ cells, indicating the good cell membrane permeability and staining ability of P1a/2c NPs in $4 \mathrm{~T} 1$ cells. The fluorescence signals of $\mathrm{P} \mathbf{1 a} / \mathbf{2} \mathbf{c}$ could be detected in both the blue-channel (400-520 nm) and green-channel (520$620 \mathrm{~nm}$ ) CLSM images of 4T1 cells at an excitation wavelength of $405 \mathrm{~nm}$ (Figure S24B-C). Closer inspection revealed that the fluorescence regions in these two channels were not well overlapped in the cytoplasm, and green spots can still be observed in some local regions of the cytoplasm in the merged image (Figure S24D-E). Based on the pH-dependent fluorescence of $\mathrm{P} 1 \mathrm{a} / 2 \mathrm{c}$, we speculated that the blue signals in the cell might result from the inherent fluorescence of P1a/2c NPs, while the green signals might mainly arise from the redder fluorescence of the protonated $\mathrm{P} \mathbf{1 a} / \mathbf{2 c}$ in acidic organelles such as lysosomes. To verify our hypothesis, a commercially available lysosomespecific staining probe LysoTracker Deep Red was used to colabel the 4T1 cells with the P1a/2c. As depicted in Figure S25, the red fluorescence from LysoTracker Deep Red in lysosomes overlapped with the green fluorescence in the cytoplasm to a large extent. The Pearson's correlation coefficient of the greenand red-channel images was calculated to be 0.78 . These results indicate that $\mathrm{P} \mathbf{1 a} / \mathbf{2 c}$ is a potential ratiometric fluorescence probe for sensing $\mathrm{pH}$ changes in live cells.

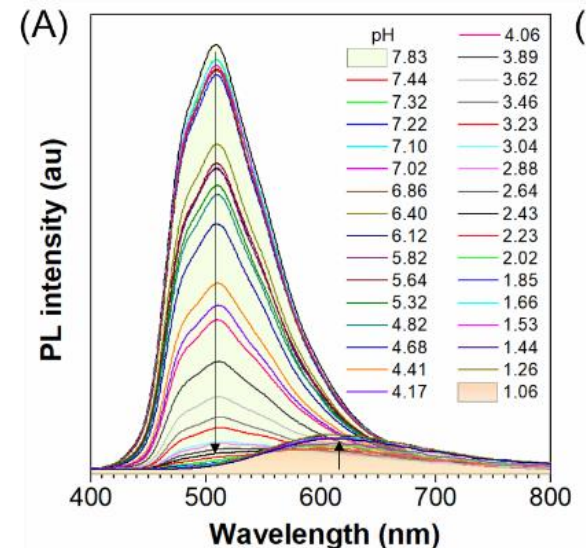

(C) Wavelength $(\mathrm{nm})$

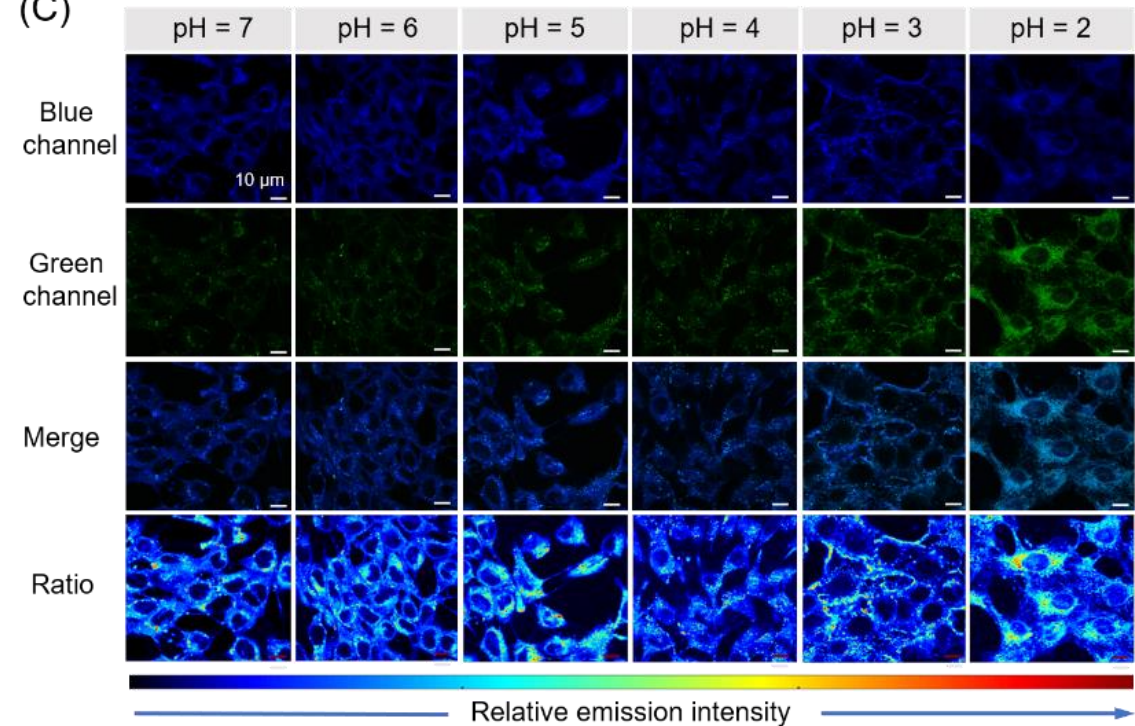

(B)

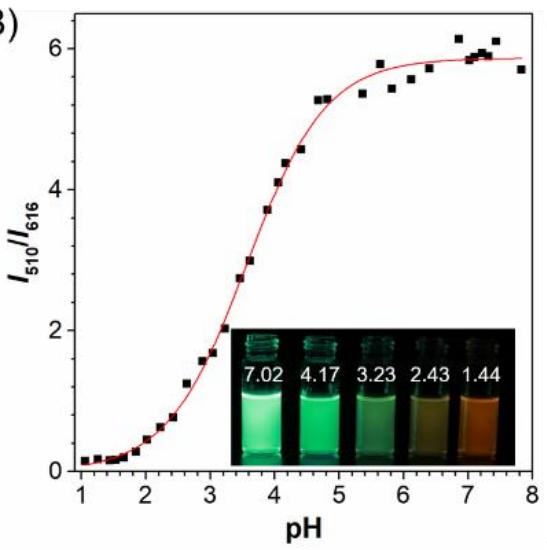

$(\mathrm{E})$
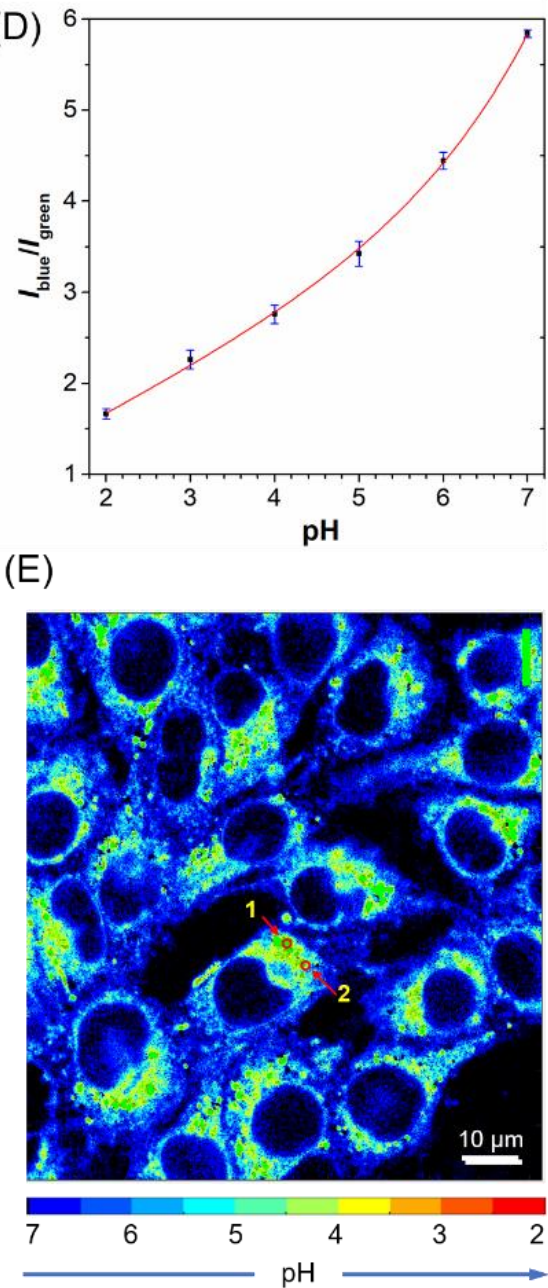

Figure 6. (A) Change of the photoluminescence (PL) spectra of P1a/2c aggregates in aqueous solutions with different pH values. Solution concentration: $10 \mu \mathrm{M}$; excitation wavelength: $340 \mathrm{~nm}$. (B) Sigmoidal fitting plot of the $\mathrm{pH}$-dependent PL intensity ratio $\left(I_{510} / I_{616}\right)$, where $I_{510}$ and $I_{616}$ denote the PL intensity at 510 and $616 \mathrm{~nm}$, respectively. Inset: fluorescence photographs taken under $365 \mathrm{~nm}$ UV irradiation. (C) CLSM images of 4T1 cells incubated with $20 \mu \mathrm{g} \mathrm{mL}{ }^{-1} \mathbf{P 1 a} / 2 \mathrm{c}$ nanoparticles in nigericin-containing buffer solutions with different $\mathrm{pH}$ values and the corresponding pseudo-color ratio images. Blue channel: excitation wavelength $=405 \mathrm{~nm}$; range of collected emission wavelength $=$ 400-520 nm. Green channel: excitation wavelength $=405 \mathrm{~nm}$; range of collected emission wavelength $=520-620 \mathrm{~nm}$. Scale bars $=10 \mu \mathrm{m}$. (D) Calibration curve showing the $\mathrm{pH}$-dependent fluorescence intensity ratio of blue to green channel ( $\left.I_{\text {blue/green }}\right)$ in live cells. (E) The $\mathrm{pH}$ mapping image for untreated 4T1 cells. 
The cytotoxicity of P1a/2c NPs was evaluated by a standard 3-(4,5-dimethyl-2-thiazolyl)-2,5-diphenyltetrazolium bromide (MTT) assay. The result shown in Figure S26A demonstrated the low cytotoxicity of $\mathrm{P} 1 \mathbf{1 a} / \mathbf{2 c}$ towards $4 \mathrm{~T} 1$ cells. The cell viability was $93 \%$ after incubation with $20 \mu \mathrm{g} / \mathrm{mL}$ of P1a/2c NPs for $24 \mathrm{~h}$, and can remain over $80 \%$ at a high concentration of P1a/2c NPs $(50 \mu \mathrm{g} / \mathrm{mL})$. Moreover, compared to the commercial probe LysoTracker Deep Red, P1a/2c NPs showed excellent photobleaching resistance (Figure S26B). The fluorescence signal of P1a/2c in 4T1 cells kept almost unchanged after continuous laser irradiation at $405 \mathrm{~nm}$ for 40 scans. The good biocompatibility and excellent photostability of P1a/2c NPs are beneficial to its application as a fluorescent bio-imaging and bio-sensing probe. To explore the application of P1a/2c NPs in the quantitative determination of intracellular $\mathrm{pH}$, we next conducted the intracellular calibration experiment of P1a/2c NPs in 4T1 cells. The intracellular and extracellular $\mathrm{pH}$ values were homogenized to be varied from 2.0 to 7.0 using $\mathrm{H}^{+} / \mathrm{K}^{+}$ionophore nigericin. ${ }^{43-44}$ As shown in Figure $6 \mathrm{C}$, the fluorescence intensity from the green channel increased dramatically as the $\mathrm{pH}$ value decreased, while that from the blue channel slightly decreased. A calibration curve in the $\mathrm{pH}$ range from 2.0 to 7.0 was generated based on the $\mathrm{pH}$-dependent fluorescence change in the above two channels (Figure 6D). The fluorescence intensity ratio of the blue to green channel $\left(I_{\text {blue }} / I_{\text {green }}\right)$ gradually increased with $\mathrm{pH}$. Pseudo-color ratio images showing the intracellular distribution of the relative emission intensity at different $\mathrm{pH}$ were obtained by processing the $I_{\text {blue }} / I_{\text {green }}$ values with Matlab. To gain direct insight into the intracellular $\mathrm{pH}$ mapping, the fluorescence images of the stained cells at varying $\mathrm{pH}$ were transformed into pseudo-color images with a $\mathrm{pH}$-dependent color bar (Figure S29). On the basis of the calibration curve shown in Figure 6D and the digital image processing method using Matlab, a pH mapping image of untreated 4T1 cells was obtained (Figure 6E). This $\mathrm{pH}$ mapping image not only can qualitatively show the general intracellular $\mathrm{pH}$ distribution of 4T1 cells in a large field of view, but also can be used for the estimation of the averaged intracellular $\mathrm{pH}$ values of organelles in $4 \mathrm{~T} 1$ cells with the assistance of the calibration curve. For example, the $\mathrm{pH}$ values at point 1 and point 2 were determined to be 5.2 and 4.5, respectively, which are the expected values for acidic organelles such as endosomes and lysosomes. ${ }^{42}$ All these results demonstrated that $\mathrm{P} \mathbf{1 a / 2 c}$ can be used as an efficient ratiometric sensing probe to quantitatively detect the intracellular $\mathrm{pH}$ changes in live cells.

\section{Killing of Cancer Cells}

Conjugated polymers with appropriate D- $\pi$-A structures have been reported to be good photosensitizers in photodynamic therapy. ${ }^{45-47}$ Considering the tunable electron accepting capability of the fused heterocyclic core via cationization, we thus investigated the photosensitive abilities of the obtained polymers and polyelectrolytes with $\mathrm{P} \mathbf{1 a} / \mathbf{2 c}$ and $\mathrm{P} \mathbf{1 a} / \mathbf{2 c}-\mathrm{I}$ as examples. Their ROS generation efficiencies were evaluated by using 2', 7'-dichlorofluorescein (DCFH) as an indicator under white light irradiation. The nonfluorescent DCFH can be sensitively converted into its highly fluorescent oxidized form (2,7-dichlorofluorescein; DCF) upon the generation of ROS. As shown in Figure 7A and Figure S28, DCFH alone remained non-emissive under white light illumination, whereas the fluorescence intensity at $525 \mathrm{~nm}$ associated with the characteristic peak of DCF was significantly enhanced in the presence of $\mathrm{P} 1 \mathrm{a} / \mathbf{2 c}$ as irradiation time increased. When the $\mathrm{pH}$ of the $\mathrm{DCFH}$ buffer was decreased to 5.37, the ROS generation efficiency of $\mathrm{P} 1 \mathbf{a} / 2 \mathrm{c}$ was higher than that in the neutral condition $(\mathrm{pH}=7.4)$. This result suggested that the cationization of $\mathrm{P} \mathbf{1 a} / \mathbf{2 c}$ could be favorable for the ROS generation due to the stronger electron accepting ability of heteroaromatic cations. Inspired by this result, the ROS generation of the cationic polyelectrolyte $\mathrm{P} \mathbf{1 a} / \mathbf{2} \mathrm{c}$ I was then measured. Compared with $\mathrm{P} \mathbf{1 a} / \mathbf{2 c}$, the emission intensity of DCF in the presence of P1a/2c-I reached nearly 730fold increase within 150 s under white light irradiation, suggesting the extraordinary ROS generation capability of P1a/2c-I.
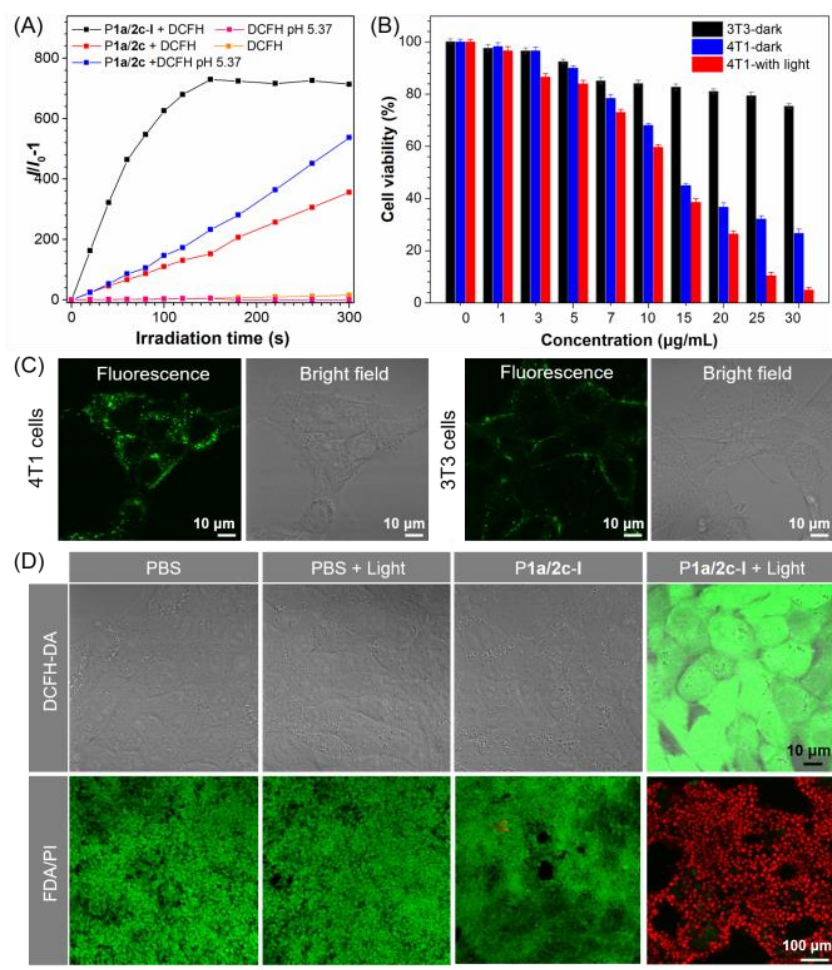

Figure 7. (A) ROS generation of P1a/2c-I $(1 \mu \mathrm{M}), \mathrm{P} 1 \mathbf{a} / \mathbf{2 c}(1 \mu \mathrm{M})$ at $\mathrm{pH}=7.40$, and $\mathrm{P} \mathbf{1 a} / \mathbf{2 c}(1 \mu \mathrm{M})$ at $\mathrm{pH}=5.37$ upon white light irradiation $\left(24 \mathrm{~mW} / \mathrm{cm}^{2}\right)$ using dichlorofluorescin $(\mathrm{DCFH})$ as an indicator. (B) Cell viability of 3T3 and 4T1 cells incubated with $\mathrm{P} 1 \mathrm{a} / 2 \mathrm{c}-\mathrm{I}$ without or with the irradiation of white light $\left(24 \mathrm{~mW} \mathrm{~cm}^{-}\right.$ ${ }^{2}, 10 \mathrm{~min}$ ) by MTT assay (mean $\pm \mathrm{SD}, \mathrm{n}=6$ ). (C) CLSM images of $4 \mathrm{~T} 1$ and $3 \mathrm{~T} 3$ cells after incubation with P1a/2c-I $\left(20 \mu \mathrm{g} \mathrm{mL}^{-1}\right)$ for $0.5 \mathrm{~h}$. Fluorescence excitation: $405 \mathrm{~nm}$, emission collected: 550 $650 \mathrm{~nm}$. (D) CLSM imaging for intracellular ROS generation (upper row) and live/dead cell assay (lower row) of 4T1 cells treated with PBS, PBS + light, P1a/2c-I $\left(30 \mu \mathrm{g} \mathrm{mL}^{-1}\right)$, and P1a/2c-I (30 $\left.\mu \mathrm{g} \mathrm{mL} \mathrm{mL}^{-1}\right)+$ light $\left(24 \mathrm{~mW} \mathrm{~cm}{ }^{-2}, 5 \mathrm{~min}\right)$ for $13 \mathrm{~h}$. The green and red colors represent live cell and dead cells, respectively.

By virtue of the high light-triggered ROS generation efficiency of P1a/2c-I, we then explored its application in photodynamic killing of cancer cells. The cytotoxicity of P1a/2c-I with and without extra white light irradiation was quantitatively examined by MTT assay. The concentration-dependent cell viability shown in Figure 7B suggested that P1a/2c-I possessed excellent tumoricidal efficacy to $4 \mathrm{~T} 1$ tumor cells via a synergistic effect of dark toxicity and phototoxicity. Under the dark condition, P1a/2c-I exhibited weak cytotoxicity to normal 3T3 cells even at high concentrations whereas the inhibiting ability for 4T1 cells was obviously stronger. This result revealed the discriminated killing ability of P1a/2c-I between normal and cancer cells. Upon white light irradiation $\left(24 \mathrm{~mW} \mathrm{~cm}^{-2}, 10 \mathrm{~min}\right)$, the killing ability of P1a/2c-I toward 4T1 cells was significantly 
enhanced with an $\mathrm{IC}_{50}$ value (the concentration causing $50 \%$ growth inhibition) of as low as $13.8 \mu \mathrm{g} \mathrm{mL}^{-1}$, demonstrating the contribution of the phototoxicity of P1a/2c-I on its tumoricidal efficacy. The difference in cytotoxicity towards cancer cells and normal cells could be attributed to the different cellular uptake levels of P1a/2c-I (Figure 7C and Figure S29). After incubation with $\mathrm{P} 1 \mathrm{a} / \mathbf{2 c}-\mathrm{I}$ for $0.5 \mathrm{~h}$, this cationic polyelectrolyte can be largely uptaken by cancer cells (4T1, HeLa and A549 cells) to show strong green fluorescence in cytoplasms, manifesting that P1a/2c-I can cross the membranes of cancer cells smoothly. By contrast, the green fluorescence was mainly observed on the cell membranes of normal cells (3T3, HUVEC and NRK-52E cells) rather than in their cytoplasms. The better internalization result of $\mathrm{P} \mathbf{1 a} / \mathbf{2 c}-\mathrm{I}$ in cancer cells could be explained by the more active cellular uptake ability of cancer cells in order to meet the nutrients demand for rapid cancer cell proliferation. ${ }^{48-50}$

Furthermore, the intracellular ROS generation was also tested by 2',7'-dichlorofluorescein diacetate (DCFH-DA) and monitored by CLSM. As shown in the upper row of Figure 7D, bright fluorescence was observed in P1a/2c-I-treated 4T1 cells under white light irradiation, while the control groups showed no obvious fluorescence. This result clearly demonstrated that P1a/2c-I can efficiently generate ROS inside live cells, which contributes its high phototoxicity against 4T1 cells. To intuitively visualize the phototherapeutic effect of P1a/2c-I, the live/dead staining experiment was carried out using fluorescein diacetate (FDA, indicator for live cells with green fluorescence) and propidium iodide (PI, indicator for dead cells with red fluorescence) double-staining protocol. As expected, nearly all the P1a/2c-I-treated cells were dead and stained with red fluorescence after white light irradiation, and negligible cell death was observed in the light irradiation alone group (Figure 7D, lower row), indicating the salient phototoxicity of P1a/2c-I as well as low side effect of the used conditions. Unexpectedly, the P1a/2c-I alone group showed strong green fluorescence signal scattered with a little red fluorescence. This result seemed to be not consistent with the dark cytotoxicity of P1a/2c-I obtained by the MTT assay, which exhibited distinct cell death at the same $\mathbf{P 1 a} / \mathbf{2 c}-\mathbf{I}$ concentration of $30 \mu \mathrm{g} \mathrm{mL}^{-1}$. We speculated that the $4 \mathrm{~T} 1$ cells might be in an early apoptotic state rather than completely dead after incubation with P1a/2c-I for $13 \mathrm{~h}$ without light. This hypothesis was further verified by the apoptosis test using the Annexin V-APC/PI detection assay. The CLSM images shown in Figures S31 revealed that P1a/2c-I can effectively induce the apoptosis of 4T1 cells after $13 \mathrm{~h}$ incubation, which also could elucidate the detailed killing mechanism of P1a/2c-I in dark. Collectively, the synergistic effects of dark toxicity and phototoxicity as well as the discrimination ability of P1a/2c-I towards cancer cells allow it to be potentially applied in photodynamic cancer therapy. ${ }^{51}$

\section{CONCLUSIONS}

In summary, we have developed a facile, straightforward, and efficient polymerization method for the in-situ generation of multiple ring-fused aza-heteroaromatic polymers. This synthetic strategy enjoys the advantages of readily available monomers, high efficiency, wide monomer scope, and high atom economy. The rhodium(III)-catalyzed $\mathrm{C}-\mathrm{H}$-activated polyannulations of $\mathrm{N}$-aryl-substituted imidazoles and internal diynes can efficiently produce a series of ring-fused PBIs with multiple aryl substituents. After reacting for merely 2 hours, the absolute molecular weights of these polymers can reach up to 24000 and the reaction yields are up to $99.6 \%$. Due to the unique imidazole-containing and multisubstituted ring-fused structures, the obtained polymers possess high thermal and morphological stability ( $T_{\mathrm{d}}$ up to $522^{\circ} \mathrm{C} ; T_{\mathrm{g}}$ up to $315^{\circ} \mathrm{C}$ ), good solution processability, high refractive index, as well as small chromic dispersion, which enable them to serve as potential heat-resistant optical coatings in advanced optoelectronic devices. Moreover, these polymers show dual-state intensive fluorescence in both solution and aggregate states. Their PL properties can be readily tuned by the postmodification reaction with iodomethane or the protonation-deprotonation process under acid-base conditions. The remarkable and ratiometric fluorescence change of polymer $\mathbf{P} \mathbf{1 a} / \mathbf{2 c}$ in response to $\mathrm{pH}$ variations make it a promising fluorescence sensor for the quantitative analysis of intracellular $\mathrm{pH}$ in live cells. Moreover, the azonia-containing polyelectrolytes synthesized by the simple $N$-methylation reaction of the ring-fused PBIs further extend their application scope to the photodynamic killing of cancer cells. The cationic polyelectrolyte P1a/2c-I with a D- $\pi$-A structure shows excellent tumoricidal efficacy via a synergistic effect of dark toxicity and phototoxicity. It is foreseeable that the facile cascade $\mathrm{C}-\mathrm{H}$-activated polyannulation strategy and the fascinating functionalities of the obtained ring-fused aza-heteroaromatic polymers in this work could bring new inspiration to polymer chemistry and promote further research on the design, modification, and applications of diversified functional heteroaromatic polymers.

\section{ASSOCIATED CONTENT}

\section{Supporting Information}

Details of the materials, methods, synthetic procedures, and characterization data (IR, NMR, HRMS, TGA, DSC, etc.); effects of time, catalyst, solvent and oxidant on polymerization; Photophysical properties of model compounds and polymers; Cell imaging data.

The Supporting Information is available free of charge on the ACS Publications website.

\section{AUTHOR INFORMATION}

\section{Corresponding Author}

*hanting@szu.edu.cn

*wangd@szu.edu.cn

*tangbenz@cuhk.edu.cn.

Author Contributions

${ }^{\#}$ Kang Wang and Saisai Yan contributed equally to this work.

\section{Notes}

The authors declare no competing financial interest.

\section{ACKNOWLEDGMENT}

This work was supported by the National Natural Science Foundation of China (grant numbers 21905176, 52122317, 22175120), the Science and Technology Plan of Shenzhen (grant numbers JCYJ20190808142403590, JCYJ20190808153415062), and the Natural Science Foundation for Distinguished Young Scholars of Guangdong Province (grant number 2020B1515020011). The authors also acknowledge the Instrumental Analysis Center of Shenzhen University.

\section{REFERENCES}

(1). Hergenrother, P. M., The Use, Design, Synthesis, and Properties of High Performance/High Temperature Polymers: An Overview. High Perform. Polym. 2003, 15 (1), 3-45.

(2). Rusanov, A. L.; Komarova, L. G., High-Performance Heterocyclic Polymers. Polymer Science: A Comprehensive Reference, 10 Volume Set 2012, 5, 537-596. 
(3). Aili, D.; Yang, J.; Jankova, K.; Henkensmeier, D.; Li, Q., From Polybenzimidazoles to Polybenzimidazoliums and Polybenzimidazolides. J. Mater. Chem. A 2020, 8 (26), 12854-12886.

(4). Yin, J.; Meng, X.; Zhang, S.; Zhang, D.; Wang, L.; Liu, C., The Effect of A Nuclear Localization Sequence on Transfection Efficacy of Genes Delivered by Cobalt(II)-Polybenzimidazole Complexes. Biomaterials 2012, 33 (31), 7884-7894.

(5). Zhu, L.; Swihart, M. T.; Lin, H., Unprecedented Size-Sieving Ability in Polybenzimidazole Doped with Polyprotic Acids for Membrane H2/CO2 Separation. Energy Environ. Sci. 2018, 11 (1), 94100.

(6). Li, J.; Wang, J.; Wu, Z.; Tao, S.; Jiang, D., Ultrafast and Stable Proton Conduction in Polybenzimidazole Covalent Organic Frameworks via Confinement and Activation. Angew. Chem., Int. Ed. 2021, 60 (23), 12918-12923.

(7). Yang, J.; Li, Q.; Cleemann, L. N.; Jensen, J. O.; Pan, C.; Bjerrum, N. J.; He, R., Crosslinked Hexafluoropropylidene Polybenzimidazole Membranes with Chloromethyl Polysulfone for Fuel Cell Applications. Adv. Energy Mater. 2013, 3 (5), 622-630.

(8). Asensio, J. A.; Sánchez, E. M.; Gómez-Romero, P., ProtonConducting Membranes Based on Benzimidazole Polymers for HighTemperature PEM Fuel Cells. A Chemical Quest. Chem. Soc. Rev. 2010, 39 (8), 3210-3239.

(9). Taublaender, M. J.; Mezzavilla, S.; Thiele, S.; Glöcklhofer, F.; Unterlass, M. M., Hydrothermal Generation of Conjugated Polymers Using the Example of Pyrrone Polymers and Polybenzimidazoles. Angew. Chem., Int. Ed. 2020, 59 (35), 15050-15060.

(10). Wang, T.; Zhang, N.; Bai, W.; Bao, Y., Fluorescent Chemosensors Based on Conjugated Polymers with N-heterocyclic Moieties: Two Secades of Progress. Polym. Chem. 2020, 11 (18), 3095-3114.

(11). Cansu-Ergun, E. G., Chemical Insight Into Benzimidazole Containing Donor-Acceptor-Donor Type П-Conjugated Polymers: Benzimidazole As An Acceptor. Polym. Rev. 2018, 58 (1), 42-62.

(12). Zhu, C.; Liu, L.; Yang, Q.; Lv, F.; Wang, S., Water-Soluble Conjugated Polymers for Imaging, Diagnosis, and Therapy. Chem. Rev. 2012, 112 (8), 4687-4735.

(13). Kaur, S.; Kanibolotsky, A. L.; Skabara, P. J., CHAPTER 18 Fused Heterocycle Polymers. In Conjugated Polymers: A Practical Guide to Synthesis, R. Soc. Chem. 2014, 387-421.

(14). Takagi, K.; Miwa, T.; Masu, H., Synthesis and Optical Properties of $\pi$-Conjugated Polymers Containing Fused Imidazole Skeleton. Macromolecules 2016, 49 (23), 8879-8887.

(15). Giri, R.; Shi, B.-F.; Engle, K. M.; Maugel, N.; Yu, J.-Q., Transition Metal-Catalyzed C-H Activation Reactions: Diastereoselectivity and Enantioselectivity. Chem. Soc. Rev. 2009, 38 (11), 3242-3272.

(16). Zhao, Q.; Meng, G.; Nolan, S. P.; Szostak, M., N-Heterocyclic Carbene Complexes in $\mathrm{C}-\mathrm{H}$ Activation Reactions. Chem. Rev. 2020, 120 (4), 1981-2048.

(17). Pouliot, J.-R.; Grenier, F.; Blaskovits, J. T.; Beaupré, S.; Leclerc, M., Direct (Hetero)arylation Polymerization: Simplicity for Conjugated Polymer Synthesis. Chem. Rev. 2016, 116 (22), 1422514274 .

(18). Suraru, S.-L.; Lee, J. A.; Luscombe, C. K., C-H Arylation in the Synthesis of $\pi$-Conjugated Polymers. ACS Macro Lett. 2016, 5 (6), 724-729.

(19). Grenier, F.; Goudreau, K.; Leclerc, M., Robust Direct (Hetero)arylation Polymerization in Biphasic Conditions. J. Am. Chem. Soc. 2017, 139 (7), 2816-2824.

(20). Bheemireddy, S. R.; Hautzinger, M. P.; Li, T.; Lee, B.; Plunkett, K. N., Conjugated Ladder Polymers by a Cyclopentannulation Polymerization. J. Am. Chem. Soc. 2017, 139 (16), 5801-5807.

(21). Liu, X.; Li, M.; Han, T.; Cao, B.; Qiu, Z.; Li, Y.; Li, Q.; Hu, Y.; Liu, Z.; Lam, J. W. Y.; Hu, X.; Tang, B. Z., In Situ Generation of Azonia-Containing Polyelectrolytes for Luminescent Photopatterning and Superbug Killing. J. Am. Chem. Soc. 2019, 141 (28), 11259-11268.

(22). Han, T.; Yao, Z.; Qiu, Z.; Zhao, Z.; Wu, K.; Wang, J.; Poon, A. W.; Lam, J. W. Y.; Tang, B. Z., Photoresponsive Spiro-Polymers Generated in Situ by $\mathrm{C}-\mathrm{H}$-activated Polyspiroannulation. Nat. Commun. 2019, 10 (1), 5483.
(23). Liu, X.; Xiao, M.; Xue, K.; Li, M.; Liu, D.; Wang, Y.; Yang, X.; Hu, Y.; Kwok, R. T. K.; Qin, A.; Zhu, C.; Lam, J. W. Y.; Tang, B. Z., Heteroaromatic Hyperbranched Polyelectrolytes: Multicomponent Polyannulation and Photodynamic Biopatterning. Angew. Chem., Int. Ed. 2021, 60 (35), 19222-19231.

(24). Liu, Y.; Zhao, Z.; Lam, J. W. Y.; Zhao, Y.; Chen, Y.; Liu, Y.; Tang, B. Z., Cascade Polyannulation of Diyne and Benzoylacetonitrile: A New Strategy for Synthesizing Functional Substituted Poly(naphthopyran)s. Macromolecules 2015, 48 (13), 4241-4249.

(25). Tokoro, Y.; Sato, H.; Fukuzawa, S.-i., Synthesis of $\pi$ Conjugated Polymers Containing Benzodipyrrole Moieties in the Main Chain through Cleavage of $\mathrm{C}-\mathrm{H}$ Bonds in 1,4Bis(acetylamino)benzene. ACS Macro Lett 2015, 4 (7), 689-692.

(26). Ge, Q.; Li, B.; Wang, B., Synthesis of Substituted Benzo[ij]imidazo[2,1,5-de]quinolizine by Rhodium(iii)-Catalyzed Multiple C-H Activation and Annulations. Org. Biomol. Chem. 2016, 14 (5), 1814-1821.

(27). Gao, M.; Lam, J. W. Y.; Liu, Y.; Li, J.; Tang, B. Z., A New Route to Functional Polymers: Atom-Economical Synthesis of Poly(pyrazolylnaphthalene)s by Rhodium-catalyzed Oxidative Polycoupling of Phenylpyrazole and Internal Diynes. Polym. Chem. 2013, 4 (9), 2841-2849.

(28). Wang, K.; Wang, H.; Li, J.; Liang, Y.; Xie, X.-Q.; Liu, J.; Gu, C.; Zhang, Y.; Zhang, G.; Liu, C.-S., Super-Stretchable and Extreme Temperature-Tolerant Supramolecular-Polymer Double-Network Eutectogels with Ultrafast in Situ Adhesion and Flexible Electrochromic Behaviour. Mater. Horiz. 2021, 8 (9), 2520-2532.

(29). Zhou, Z.; Long, Y.; Chen, X.; Yang, T.; Zhao, J.; Meng, Y.; Chi, Z.; Liu, S.; Chen, X.; Aldred, M. P.; Xu, J.; Zhang, Y., Preserving High-Efficiency Luminescence Characteristics of an AggregationInduced Emission-Active Fluorophore in Thermostable Amorphous Polymers. ACS Appl. Mater. Interfaces 2020, 12 (30), 34198-34207.

(30). Li, H.; Zhou, Y.; Liu, Y.; Li, L.; Liu, Y.; Wang, Q., Dielectric Polymers for High-Temperature Capacitive Energy Storage. Chem. Soc. Rev. 2021, 50 (11), 6369-6400.

(31). Higashihara, T.; Ueda, M., Recent Progress in High Refractive Index Polymers. Macromolecules 2015, 48 (7), 1915-1929.

(32). Mark, J. E. Polymer Data Handbook; Oxford University Press: New York, 2009.

(33). Sapozhnikov, D. A.; Baiminov, B. A.; Vygodskii, Y. S., Highly Heat-Resistant Polymeric Coatings of Optical Fibers. Polym. Sci., Ser. C 2020, 62 (2), 165-171.

(34). Mei, J.; Leung, N. L. C.; Kwok, R. T. K.; Lam, J. W. Y.; Tang, B. Z., Aggregation-Induced Emission: Together We Shine, United We Soar! Chem. Rev. 2015, 115 (21), 11718-11940.

(35). Dang, D.; Qiu, Z.; Han, T.; Liu, Y.; Chen, M.; Kwok, R. T. K.; Lam, J. W. Y.; Tang, B. Z., $1+1 \gg 2$ : Dramatically Enhancing the Emission Efficiency of TPE-Based AIEgens but Keeping their Emission Color through Tailored Alkyl Linkages. Adv. Funct. Mater. 2018, 28 (16), 1707210.

(36). Lee, M. H.; Han, J. H.; Lee, J. H.; Park, N.; Kumar, R.; Kang, C.; Kim, J. S., Two-Color Probe to Monitor a Wide Range of $\mathrm{pH}$ Values in Cells. Angew. Chem., Int. Ed. 2013, 52 (24), 6206-6209.

(37). Wan, Q.; Chen, S.; Shi, W.; Li, L.; Ma, H., Lysosomal pH Rise during Heat Shock Monitored by a Lysosome-Targeting Near-Infrared Ratiometric Fluorescent Probe. Angew. Chem., Int. Ed. 2014, 53 (41), 10916-10920.

(38). Webb, B. A.; Chimenti, M.; Jacobson, M. P.; Barber, D. L., Dysregulated pH: a Perfect Storm for Cancer Progression. Nat. Rev. Cancer 2011, 11 (9), 671-677.

(39). Bao, Y.; De Keersmaecker, H.; Corneillie, S.; Yu, F.; Mizuno, H.; Zhang, G.; Hofkens, J.; Mendrek, B.; Kowalczuk, A.; Smet, M., Tunable Ratiometric Fluorescence Sensing of Intracellular $\mathrm{pH}$ by Aggregation-Induced Emission-Active Hyperbranched Polymer Nanoparticles. Chem. Mater. 2015, 27 (9), 3450-3455.

(40). Lu, Y.; Aimetti, A. A.; Langer, R.; Gu, Z., Bioresponsive materials. Nat. Rev. Mater. 2016, 2 (1), 16075.

(41). Han, J.; Burgess, K., Fluorescent Indicators for Intracellular pH. Chem. Rev. 2010, 110 (5), 2709-2728.

(42). Casey, J. R.; Grinstein, S.; Orlowski, J., Sensors and regulators of intracellular pH. Nat. Rev. Mol. Cell Biol. 2010, 11 (1), 50-61. 
(43). Shi, W.; Li, X.; Ma, H., A Tunable Ratiometric pH Sensor Based on Carbon Nanodots for the Quantitative Measurement of the Intracellular $\mathrm{pH}$ of Whole Cells. Angew. Chem., Int. Ed. 2012, 51 (26), 6432-6435.

(44). Kim, H. J.; Heo, C. H.; Kim, H. M., Benzimidazole-Based Ratiometric Two-Photon Fluorescent Probes for Acidic pH in Live Cells and Tissues. J. Am. Chem. Soc. 2013, 135 (47), 17969-17977.

(45). Wu, W.; Mao, D.; Xu, S.; Kenry; Hu, F.; Li, X.; Kong, D.; Liu, B., Polymerization-Enhanced Photosensitization. Chem 2018, 4 (8), 1937-1951.

(46). Zhou, T.; Hu, R.; Wang, L.; Qiu, Y.; Zhang, G.; Deng, Q.; Zhang, H.; Yin, P.; Situ, B.; Zhan, C.; Qin, A.; Tang, B. Z., An AIEActive Conjugated Polymer with High ROS-Generation Ability and Biocompatibility for Efficient Photodynamic Therapy of Bacterial Infections. Angew. Chem., Int. Ed. 2020, 59 (25), 9952-9956.

(47). Kang, M.; Zhang, Z.; Song, N.; Li, M.; Sun, P.; Chen, X.; Wang, D.; Tang, B. Z., Aggregation-Enhanced Theranostics: AIE Sparkles in Biomedical Field. Aggregate. 2020, 1 (1), 80-106.
(48). Danquah, M. K.; Zhang, X. A.; Mahato, R. I., Extravasation of Polymeric Nanomedicines Across Tumor Vasculature. Adv. Drug Delivery Rev. 2011, 63 (8), 623-639.

(49). Danhier, F.; Feron, O.; Préat, V., To Exploit the Tumor Microenvironment: Passive and Active Tumor Targeting of Nanocarriers for Anti-Cancer Drug Delivery. J. Controlled Release 2010, 148 (2), 135-146.

(50). Nicolas, J.; Mura, S.; Brambilla, D.; Mackiewicz, N.; Couvreur, P., Design, Functionalization Strategies and Biomedical Applications of Targeted Biodegradable/Biocompatible Polymer-Based Nanocarriers for Drug Delivery. Chem. Soc. Rev. 2013, 42 (3), 11471235.

(51). Ma, Y.; Zhuang, Z.; Xing, L.; Li, J.; Yang, Z.; Ji, S.; Hu, R.; Zhao, Z.; Huo, Y.; Tang, B. Z., The AIE-Active Dual-Cationic Molecular Engineering: Synergistic Effect of Dark Toxicity and Phototoxicity for Anticancer Therapy. Adv. Funct. Mater. 2021, 31 (49), 2106988.

\section{For Table of Contents Only}

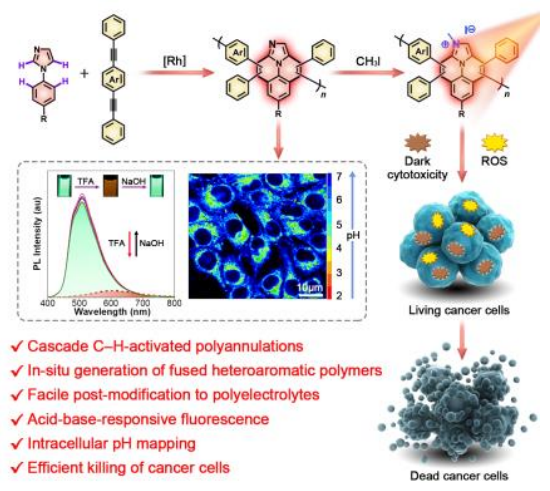

